\title{
Hedge Fund Characteristics and Performance Persistence*
}

\author{
Manuel Ammann, Otto Huber, and Markus Schmid ${ }^{\dagger}$
}

This Version: August 2010

\begin{abstract}
In this paper, we investigate the performance persistence of hedge funds over time horizons between 6 and 36 months based on a merged sample from the Lipper/TASS and CISDM databases for the time period from 1994 to 2008. Unlike previous literature, we use a panel probit regression approach to identify fund characteristics that are significantly related to performance persistence. We then investigate the performance of two-way sorted portfolios where sorting is based on past performance and one of the additional fund characteristics identified as persistence-enhancing in the probit analysis. We find statistically and economically significant performance persistence for time horizons of up to 36 months. Although we identify several fund characteristics that are strongly correlated with the probability of observing performance persistence, we find only one fund characteristic, a strategy distinctiveness index that attempts to measure manager skills and the uniqueness of the hedge fund's trading strategies, to have the ability to systematically improve performance persistence up to a time horizon of 24 months. The economic magnitude of this improvement amounts to a sizeable increase in alpha by approximately $4.0 \%$ and $2.3 \%$ p.a. for annual and biennial rebalancing, respectively.
\end{abstract}

JEL Classification: G11, G12, G23

Keywords: Hedge Funds; Performance; Alpha; Factor Models; Performance Persistence

${ }^{*}$ We thank John Doukas (the editor), Günter Franke, Ferdinand Graf, Daniel Hoechle, Jens Jackwerth, Samuel Manser, Paul Söderlind, Evert Wipplinger, an anonymous referee, the participants of the Man Investments Quant Forum at St. Anne's College in Oxford, and the participants of the joint research workshop of the University of St. Gallen and the University of Konstanz for their valuable comments.

${ }^{\dagger}$ Manuel Ammann is at the University of St. Gallen, Switzerland, Otto Huber is with Credit Suisse Securities (USA) LLC and at the University of St. Gallen, and Markus Schmid is at the University of Mannheim, Germany. Corresponding author: Markus Schmid, University of Mannheim, Finance Area, Chair for Business Administration and Corporate Governance, D-68131 Mannheim, Germany; +49 (621) 181-3754; schmid@bwl.unimannheim.de. 


\section{Introduction}

Although a large number of papers have been published on performance persistence of hedge funds, no common consensus has yet been found whether hedge fund performance persists or not. The majority of papers find short-term persistence (e.g., Agarwal and Naik, 2000; Harri and Brorsen, 2004; Manser and Schmid, 2009) but there is only little support for long-term persistence (e.g., Edwards and Caglayan, 2001; Jagannathan et al., 2010). However, in light of notice and redemption periods, the knowledge about short-term performance persistence of hedge funds does not add a great deal of value for an investor.

In this paper, we therefore focus on long-term performance persistence and attempt to form hedge fund portfolios that consistently outperform their peers. Unlike previous studies, we investigate the performance persistence of two-way sorted portfolios where the sorting is based on past performance and various additional fund characteristics. We use a panel probit regression approach to identify fund characteristics that are significantly related to performance persistence. Moreover, in this study we focus on the investment performance of sorted portfolios instead of investigating the statistical significance of hedge fund performance persistence only. Our results indicate statistically significant and economically substantial performance persistence for time horizons of up to 36 months which can be further improved when a strategy distinctiveness index, which attempts to measure manager skills and the uniqueness of the hedge fund's trading strategies, is used as a second sorting criterion.

In one of the earlier papers on performance persistence, Agarwal and Naik (2000) find evidence for persistence in alpha and in appraisal ratio based on a one-factor model including strategy indices only at quarterly horizons - especially among losers. Capocci and Huebner (2004) report no performance persistence for the best and worst performing hedge funds (as measured by alpha deciles), but for the mediocre performers. Bares et al. (2003) apply a non-parametric approach to individual funds and, alternatively, an eight-factor risk model approach to fund portfolios and find evidence of performance persistence only over one- to three-month horizons. Harri and Brorsen (2004) report short-term persistence over three to four months, with the biggest effect in the first month based on simple regressions of returns 
on lagged returns. Capocci (2007) proposes an adapted Sharpe ratio, termed "Sharpe score", which divides the return of a fund by a risk figure that takes not only variance into consideration but also skewness and kurtosis, weighted with a factor representing an investor's risk aversion. Capocci (2007) then shows that hedge funds with the highest Sharpe score over a three-year period significantly outperform a 10-factor and a 14-factor model over the subsequent year. Boyson (2008) shows that controlling for style is important when analyzing the performance persistence of hedge funds. In addition, she identifies manager tenure as an additional important factor to be included in the factor model used to test for performance persistence. While Boyson (2008) finds no evidence of performance persistence when only common risk factors are accounted for, she reports persistence at the quarterly time horizon when manager tenure is accounted for. Performance persistence is strongest for young managers with a positive alpha in the past. Fung et al. (2008) investigate the relationship between performance persistence and fund flows for funds of hedge funds. When controlling for fund flows on a single fund level, they find that funds with positive and significant alpha in the past are less likely to achieve a positive and significant alpha in the future when they experience above median capital inflows. They argue that this finding indicates capacity constraints at the single hedge fund level. Manser and Schmid (2009) investigate the performance persistence of equity long/short hedge funds. They report persistence in the alpha from a Carhart (1997) four-factor model and in the Sharpe ratio for time horizons of up to one year and for the worst performing funds also on the biennial horizon.

Based on a six-factor model, Edwards and Caglayan (2001) find one- and two-year alpha persistence for winners and loser hedge funds. Kosowski et al. (2007) use a seven-factor model and apply a bootstrap procedure as well as Bayesian measures to estimate hedge fund performance. When investigating performance-ranked portfolios, they find performance persistence over a one-year horizon. Jagannathan et al. (2010) find even evidence for threeyear alpha persistence, based on a three-factor model including the market excess return and two style indices, among well performing funds but no persistence among poorly performing funds. A recent overview of the literature on performance persistence of hedge funds is provided by Eling (2009). He concludes that the lack of consensus in the literature is rather 
due to differences in the methodological approach used to test persistence than to the measure of performance used.

In this paper, we investigate the performance persistence of hedge funds over time horizons between 6 and 36 months based on a merged sample from the Lipper/TASS and CISDM databases for the time period from 1994 to 2008. We attempt to improve performance persistence by identifying fund characteristics that are related to the probability of observing performance persistence. We estimate panel probit regressions of an indicator variable for whether a fund exhibits performance persistence on a number of fund characteristics. The fund characteristics we include in this analysis are fund size, fund age, relative fund flows, a dummy variable whether the fund is closed to new investments, two variables related to a fund's liquidity, i.e., the length of the notice and the length of the redemption period, management and incentive fees, leverage, and a dummy variable for whether the fund management is personally invested in the fund. Moreover, we use a 'Strategy Distinctiveness Index' (SDI) as originally suggested by Wang and Zheng (2008), defined as one minus the r-square of a fund's 24 monthly historical returns regressed against an equally-weighted strategy index. As funds within a certain strategy may exhibit more dispersion in SDI than funds within other strategies, we control for such strategy-effects by standardizing the SDI by subtracting the average SDI within the same strategy and dividing by the standard deviation of SDI within this strategy. The SDI measures the percentage of total variance in fund returns that cannot be explained by the returns of its peers. Hence, the higher SDI, the more distinctive, and presumably the more successful, is the fund's investment strategy. Wang and Zheng (2008) show that this index is a good predictor for the future performance of a fund. Consistently, Titman and Tiu (2008) find that hedge funds with a lower r-square from a stepwise based factor model over the last 24 months outperform in terms of raw returns and Sharpe ratios. Moreover, they find performance persistence in Sharpe ratios over one year horizons for these hedge funds.

The study closest to ours is Kumar (2008) who also investigates whether certain fund characteristics are significantly related to hedge fund performance persistence. Kumar (2008) hypothesizes that superior (lower) manager skill is expected to be associated with better 
(worse) performance in any given period (see also Wang and Zheng, 2008). She uses fund size, fund age, as well as management and incentive fees as proxies for manager skill and hypothesizes that larger and older funds as well as funds with higher fees are indicative of higher manager skills. Consistent with her hypotheses, she finds all these characteristics to be positively related to performance persistence. We carry the analysis in Kumar (2008) at least two steps further. First, we use a fund characteristic that specifically and more directly measures the fund manager's skills. Second, we do not only assess the statistical but also the economic significance of performance persistence. In fact, consistent with Kumar (2008), we find many fund characteristics to be significantly related to performance persistence. However, only one of the 15 characteristics we consider, the SDI, significantly increases the returns of investment strategies based on past performance and such additional fund characteristics. ${ }^{1}$

We investigate performance persistence based on the portfolio approach of Hendricks et al. (1993), which has been used to analyze performance persistence of mutual funds by Carhart (1997), for example. Instead of forming portfolios only based on past performance, we use twoway sorts and additionally use the fund characteristics identified as "persistence-enhancing" in the probit regressions. The performance of these sorted portfolios is then tested out-of-sample over the subsequent period. After each tracking period the sorting procedure is repeated. To assess hedge fund performance, we use two alternative alphas to ensure the robustness of our results with respect to the choice of the factor model. The first alpha is based on a factor model in which we select the risk factors based on a stepwise regression approach. The second alpha is based on the widely used seven-factor model proposed by Fung and Hsieh (2004).

We attempt to carefully account for the various biases in hedge fund data. We eliminate a survivorship bias by including live and dead funds in our sample and restricting the sample period to the post-1993 period, when both TASS and CISDM started to keep all hedge funds which stopped reporting in the database. As TASS provides information on when funds actually started to report to the database, we are able to eliminate the backfill bias for a large part of our sample by deleting all backfilled observations. For funds included in CISDM

\footnotetext{
${ }^{1}$ In addition, we use a more comprehensive factor model to assess alpha, more fund characteristics, and investigate persistence over longer time horizons.
} 
only, we follow common practice and delete the first 12 observations. Most importantly, we use the approach suggested by Getmansky et al. (2004a) to transform the presumably smoothed, serially correlated returns in our two databases into the unobserved (or "true") desmoothed returns. This is particularly important for studies investigating performance persistence as positive serial correlation will increase the observed persistence.

The results from the probit analyses show that all fund characteristics we consider are significantly related to the probability of observing performance persistence. The coefficients on all fund characteristics, however, exhibit opposite signs for winner and for loser persistence. Hence, the direction of the correlation runs in opposite directions for the performance persistence of well performing and the persistence of poorly performing hedge funds. SDI, fund size, relative fund flows, the length of the notice and the redemption period, a dummy variable whether the fund is closed to new investments, and management and incentive (for the 12-month horizon only) fees are all positively while fund age is negatively related to the probability of observing positive (i.e., winner) performance persistence and vice versa for negative (i.e., loser) performance persistence. When we regress hedge fund alpha on the very same fund characteristics, we find the characteristics that are positively related to winner persistence also to be positively related to alpha-with two exceptions (whether the fund is closed to new investments and incentive fees for the alpha based on the stepwise regression approach).

When assessing performance persistence based on the portfolio approach of Hendricks et al. (1993), we find a statistically and economically significant performance persistence for time horizons of up to 36 months. The difference in monthly alpha based on a stepwise regression model between the quintile-portfolio consisting of the historically best performing hedge funds and the quintile-portfolio consisting of the historically worst performing hedge funds amounts to a statistically significant and economically sizeable $2.80 \%$ monthly alpha for semi-annual rebalancing horizons, $2.29 \%$ for annual rebalancing horizons, $1.61 \%$ for biennial rebalancing horizons, and $0.99 \%$ for triennial rebalancing horizons. We then attempt to improve performance persistence by using two-way sorted portfolios based on historical performance and fund characteristics identified to be positively correlated with persistence in 
the probit regressions. However, we find the SDI to be the only fund characteristic with the ability to systematically improve performance persistence. Over the 6-month horizon the difference in monthly alpha increases to $3.10 \%$ when using the SDI as a second sorting criterion (an increase in alpha of $0.30 \%$ per month or $3.60 \%$ p.a.), over the 12 -month horizon to $2.62 \%$ (an increase in alpha of $0.33 \%$ per month or $3.96 \%$ p.a.), and over the 24 -month horizon to $1.80 \%$ (an increase in alpha of $0.19 \%$ per month or $2.28 \%$ p.a.). Over the 36 -month horizon, SDI does not positively contribute to portfolio returns anymore. These results are robust to various changes in the test specifications including the factor model on which alpha is based, changing the order of the sorting criterions in the two-way sorts, alternative definitions of the SDI variable, and the quantiles used to form portfolios (i.e., median, tercile, quartile, and quintile). Only during the credit crisis of 2008, the positive contribution of the SDI disappears indicating that high-SDI funds may take on larger idiosyncratic risks that show up in lower returns during crisis periods.

The remainder of the paper is organized as follows. Section 2 describes the dataset and variables and explains our methodological approach to assess performance persistence. Section 3 presents the results from the empirical analyses and Section 4 concludes.

\section{Data and Variables}

\subsection{Sample selection and data}

We use a merged sample combining the hedge funds included in the Lipper/TASS and the CISDM databases covering the time period from January 1994 to December 2008. We first clean our sample for duplicate entries of specific hedge funds within each individual database (e.g., due to multiple share classes and onshore and offshore vehicles of some funds). Second, we use a matching algorithm based on fund names, the strategy classification, and return correlation to remove duplicate entries resulting from merging the two databases. We attempt to minimize the survivorship bias by including live and dead funds in our sample and restricting the sample period to the post-1993 period, when both TASS and CISDM started to keep all hedge funds which stopped reporting in the database. We control for the backfilling bias (or 
instant history bias) by deleting all backfilled entries which were added to the database before a fund started reporting to the database. This date is known for roughly $95 \%$ of all funds in our sample stemming from the TASS database. For the remaining $5 \%$ of the funds from the TASS database as well as for all funds from the CISDM database, we follow common practice and delete the first 12 return observations (e.g., Fung and Hsieh, 2000; Edwards and Caglayan, 2001). ${ }^{2}$

As we estimate alpha based on rolling 24-month window regressions, we require at least 24 non-backfilled return observations for a fund to be included in our analysis. ${ }^{3}$ This requirement may introduce a sampling bias. However, Fung and Hsieh (2000) investigate this bias, which they call multi-period sampling bias, by comparing the average returns of all funds in the sample to the average returns of the funds with at least a 24-month history of returns, and find it to be very small. ${ }^{4}$ Furthermore, we exclude funds of hedge funds, hedge funds denoted in a currency other than USD, and funds whose assets under management do not exceed USD 5 millions at least once during their non-backfilled observations. ${ }^{5}$ After all these adjustments, we are left with a sample of 4,311 hedge funds with total assets under management of USD 403bn. ${ }^{6}$

\footnotetext{
${ }^{2}$ The backfill bias in our sample, calculated as difference in the return of the equally-weighted portfolio of all return observations and the portfolio that only includes non-backfilled returns, amounts to 3.2 basis points per month. For the strategy-indices, this amount varies between 0.9 basis points (Funds of Funds) to 20.2 basis points (Emerging Markets). This compares to Fung and Hsieh (2000) who find a monthly bias of 11.7 basis points for hedge funds and 20 basis points for CTAs over the period 1989 to 1997. Malkiel and Atanu (2005) calculate the backfill bias by comparing the average backfilled hedge fund return with the average non-backfilled return. They report a monthly backfill bias of 61 basis points per month for the period 1994 to 2003. This compares to 38 basis points in our sample or 44 basis points if the same period is considered.
}

${ }^{3}$ When investigating 36-month performance persistence, we require at least 36 non-backfilled return observations for a fund to be included in our analysis.

${ }^{4}$ In robustness checks, we alternatively require at least 36,48 , or 60 non-backfilled return observations. The number of hedge funds in our sample decreases to 3,366, 2,635, and 2,051 funds, respectively. However, our results remain qualitatively unchanged while all portfolio returns increase by approximately two to three basis points per additional year of return data we require. This finding is consistent with the multi-period sampling bias results in Fung and Hsieh (2000).

${ }^{5}$ We exclude fund of hedge funds from our sample as SDI is no meaningful measure of strategy distinctiveness for them (e.g., see Wang and Zheng, 2008). Including fund of hedge funds in our analysis does not qualitatively change our results. However, as expected, the increase in performance persistence attributable to additionally sorting for SDI is limited (and at the strategy level the second lowest after fixed income arbitrage).

${ }^{6}$ According to the TASS Asset Flow Report of Q4, 2009 the hedge fund industry amounted to an estimated USD 1,210bn at the end of 2008 (excluding funds of funds). Our sample therefore covers roughly one third of the total assets under management of the industry. 
The illiquidity of some of the markets in which the hedge funds are invested might have an influence on the reported returns. Driven by the fact that hedge funds avail the possibility to invest in highly illiquid assets without daily market prices and by the fact that the reported returns are only audited on an annual basis, Agarwal and Naik (2000) point out that some intra-year persistence may be caused by stale prices. In order to adjust for the bias of these stale valuations, the return series of our sample are desmoothed as suggested by Getmansky et al. (2004a). ${ }^{7}$

Getmansky et al. (2004a) demonstrate that instead of the (serially uncorrelated) true returns of a fund $\left(R_{t}\right)$, we only observe reported returns of the funds $\left(R_{t}^{o}\right)$, which feature the following relationship with actual returns:

$$
\begin{aligned}
& R_{t}^{o}=\theta_{0} R_{t}+\theta_{1} R_{t-1}+\cdots+\theta_{k} R_{t-k} \\
& \text { with } \theta_{j} \in[0,1], \quad j=0, \ldots, k \\
& \text { and } \quad 1=\theta_{0}+\theta_{1}+\cdots+\theta_{k}
\end{aligned}
$$

In this paper we set $k$ equal to two and estimate $\theta_{0}, \theta_{1}$, and $\theta_{2}$ for each hedge fund strategy by estimating this $\mathrm{MA}(2)$ model with maximum likelihood. ${ }^{8}$ We use these thetas to obtain desmoothed returns which are then included as dependent variables in our multi-factor models.

\subsection{Performance measurement}

In order to control for the funds' systematic risk exposures, we mainly focus on performance persistence in alpha. ${ }^{9}$ While there is extensive literature on hedge fund performance measurement, there is no consensus so far on which factors to include in a multi-factor model. In

\footnotetext{
${ }^{7}$ Jagannathan et al. (2010) and Ammann et al. (2010) find that this procedure of desmoothing the returns leads to a reduction of hedge fund alpha.

${ }^{8}$ As Getmansky et al. (2004a), we use a standard MA(k) estimation package (Stata) and transform the resulting estimates by dividing each theta by $1+\theta_{1}+\theta_{2}$ to satisfy Equation (3). In contrast, and also consistent with Getmansky et al. (2004a), we do not impose Equation (2) when estimating the thetas and use this restriction as a specification test.
}

${ }^{9}$ Alternatively, we also investigate the persistence in raw-returns. 
an attempt to capture the different investment styles and to minimize the risk of omitted risk factors, we use a systematic procedure to select relevant factors among those frequently used in prior literature. Due to limits of degrees of freedom in estimating the model, we attempt to keep the amount of factors included in the factor model as low as possible, while still being able to describe the investment opportunities available to hedge funds as appropriately as possible. We follow Agarwal and Naik (2004), Titman and Tiu (2008), and Ammann et al. (2010) and use stepwise regressions for the selection of the risk factors to be included in our factor models. For the selection procedure we start with 23 risk factors (see Appendix A). We then regress the returns of an equally-weighted index of all funds within a strategy in our sample on the returns of these factors. The stepwise regression approach is based on the t-values of the slope coefficients over the entire sample period with constant coefficients. A factor is added to the model when its marginal significance exceeds the $95 \%$ level. We drop any previously chosen factor which is not simultaneously significant with all other factors at least on a $90 \%$ confidence level. This iterative procedure is continued until a maximum of seven factors for each hedge fund strategy is obtained or no more significant factors can be identified. We employ the identical risk factors for all funds within a strategy and keep them for the entire sample period.

To estimate hedge fund alpha based on a factor model, most papers use either zero investment factors or excess returns of buy and hold factors above the risk free rate. ${ }^{10}$ The factors we consider include fungible factors of the following asset classes: equities, bonds and credit, interest rates, currencies, options, volatility, dynamic trading strategies, commodities, real estate, and convertible bonds. Most of these factors are excess returns above the risk free rate (i.e., the one-month T-bill); some are zero-investment portfolios. We account for the possibility of non-linear factor exposures of hedge funds by including option-based factors in our factor models. These include the returns of the dynamic trading strategies (based on lookback option straddles) proposed by Fung and Hsieh (2001) and the returns of European at-the-money (ATM) call and put options on the S\&P 500 index as suggested by Agarwal

\footnotetext{
${ }^{10}$ Such papers include Fama and French (1993), Carhart (1997), Edwards and Caglayan (2001), Ennis and Sebastian (2003), Agarwal and Naik (2004), Capocci and Huebner (2004), Ammann and Moerth (2008), and Titman and Tiu (2008).
} 
and Naik (2004). Unlike Agarwal and Naik (2004), who use ATM options and 1\% out-of-themoney (OTM) options, we include ATM options and 7.5\% OTM options. We use options that are further out-of-the-money in an attempt to capture the possibility of hedge funds to sell tail risk and not to include too higly correlated risk factors in our model. The complete set of factors considered for the selection procedure is listed in Appendix A. The choice of factors resulting from the stepwise procedure for each strategy is reported in Table 1. Henceforth, we label this alpha based on the stepwise regression approach 'SW alpha'.

We compare the results of these factor models obtained by stepwise regressions with those from the widely used seven-factor model of Fung and Hsieh (2004). Titman and Tiu (2008), for example, show the alpha from their stepwise approach to be lower than that resulting from the seven-factor model and the r-squares to be significantly higher. The seven factors proposed by Fung and Hsieh (2004) include three trend-following risk factors on bonds, currencies, and commodities, two equity-oriented risk factors (the S\&P 500 monthly total return and a size spread factor - either the Wilshire Small Cap 1750 minus Wilshire Large Cap 750 monthly return or Russel 2000 TR minus S\&P 500 TR), and two bond-oriented risk factors (the monthly change in the 10-year treasury constant maturity yield and the monthly change in spread between the Moody's Baa yield less the 10-year treasury constant maturity yield). The changes in spreads are both first differences of the levels. The alpha based on the Fung and Hsieh (2004) seven-factor model is henceforth termed 'FH alpha'.

One major concern with the stepwise regression approach is that the methodology is prone to data mining and may lead to an over-fitting in the in-sample period while performing very poorly out-of-sample. We test the out-of-sample performance of our stepwise regression models by comparing the average r-square obtained in alpha regressions over the second half of our sample period (the 90 months from July 2001 to December 2008) using the risk factors obtained in stepwise regressions run either for the first sample half (January 1994 to June 2001) or stepwise regressions run for the second half of our sample period (July 2001 to December 2008). Hence, we compare the r-square obtained in out-of-sample regressions to those from in-sample regressions where the stepwise approach was run over the same sample period as the subsequent alpha regressions. We do this on the strategy level and aggregate 
the results over all 10 strategies. Most importantly, over all strategies, we find an average in-sample r-square of 0.724 that compares to an out-of-sample r-square of 0.666 . Hence, the average out-of-sample r-square is reasonably high and only slightly reduced as compared to the in-sample r-square. For comparison reasons, the average r-square from the FH model over the same time period is substantially lower than both the in-sample and the out-of-sample r-square from the stepwise models (0.507). This result also holds at the strategy level with two exceptions. For Dedicated Short Bias and Fixed Income Arbitrage the r-square from the FH model is smaller than the in-sample but larger than the out-of-sample r-square from the SW model. However, in both cases all three r-squares are very similar (Dedicated Short Bias: 0.874, 0.879, 0.913; Fixed Income Arbitrage strategy: 0.602, 0.608, 0.659).

Finally, we investigate which factors chosen in our stepwise regressions and not included in the Fung and Hsieh (2004) seven-factor model are responsible for the differences in the model fit between the SW regressions and the FH regressions. When comparing the factor choice (as reported in Table 1) and level of significance in the SW factor model to the seven FH factors and their significance, we find substantial differences for some of the strategies. To save space, we do not report the results in a table and concentrate on the three strategies that exhibit the largest differences in adjusted r-squares when applying the two alternative factor models to the strategy index. These are the strategies Equity Market Neutral (rsquare of $47.0 \%$ vs. $21.4 \%$ ), Global Macro (35.4\% vs. 18.8\%), and Emerging Markets $(80.4 \%$ vs. 44.5\%). For the Equity Market Neutral strategy, the SW approach chooses the following five factors, none of which is included in the seven $\mathrm{FH}$ factors: momentum factor, 92.5\% ATM put option on the S\&P 500 index, 107.5\% OTM call option on the S\&P 500 index, high yield bond index, and the return of a stock-based primitive trend following strategy. All these factors are significant at the $1 \%$ level while of the seven $\mathrm{FH}$ factors only the bond and the S\&P 500 return factors are significant at the $10 \%$ and $1 \%$ level, respectively. For the Global Macro strategy, the SW approach selects the following five factors: 3m TED spread, world government bond index, MSCI emerging markets index, the return of a currency-based primitive trend following strategy, and the momentum factor. Only the last factor, the return of a currency-based primitive trend following strategy, is among the seven FH factors. Again 
all five factors are significant at the $1 \%$ level while in the $\mathrm{FH}$ model only three factors are significant at the $1 \%$ level (the currency-based primitive trend following strategy, the S\&P 500 total return, and the monthly change in the 10-year treasury constant maturity yield) and one other factor at the 10\% level (SMB). Finally, for the Emerging Markets strategy, the SW approach selects the following three risk factors: momentum factor, MSCI emerging markets factor, and dollar index spot factor. Again, all three factors are significant at the $1 \%$ level, not surprisingly with the highest significance level for the emerging markets factor (t-value of $13.85 \%$ ). Of the seven $\mathrm{FH}$ factors only two are significant (also at the $1 \%$ level), the S\&P 500 total return and SMB. Hence, for many strategies, we find substantial differences in the factor choice between the SW and FH models, whereas some the most highly significant, and economically (as well as intuitively) meaningful factors are missing in the FH model. For other strategies, however, the average adjusted r-squares (and the choice of the risk factors) are much more similar between the two risk models, examples being Managed Futures (rsquare of $38.8 \%$ vs. $32.0 \%$ ) and Long /Short Equity (89.6\% vs. $79.6 \%$ ).

\subsection{Measuring performance persistence}

We classify a fund to exhibit performance persistence if it is a winner (or a loser) in two subsequent non-overlapping time periods. A fund is classified as being a winner (loser) if it exhibits an above-median (below-median) alpha in the respective time period. ${ }^{11}$ Time periods used include 6 months as well as 1,2, and 3 years. We test the robustness of the results by alternatively using alphas based on both, our stepwise regression approach and the FH factor model.

Next, we attempt to identify fund characteristics which are correlated with the funds' performance persistence. We do this by estimating panel probit regressions of an indicator variable for whether a hedge fund exhibits performance persistence (1) or not (0) on a number of fund characteristics. We use three alternative specifications of this performance persistence dummy variable. The first variable, WWLL, equals one for all fund-months for which the

\footnotetext{
${ }^{11}$ In robustness checks, we also use higher quantiles than the median to classify funds as winners or losers including the $70 \% / 30 \%$ and $80 \% / 20 \%$ quantiles.
} 
fund is either a winner or a loser in two subsequent non-overlapping time periods and zero otherwise. The second specification, WW, measures only the persistence of winner funds and thus is equal to one for all fund-months for which the fund is a winner in two subsequent non-overlapping time periods and zero otherwise. The third specification, LL, measures only the persistence of loser funds and is equal to one for all fund-months for which the fund is a loser in two subsequent non-overlapping time periods and zero otherwise.

Finally, each period, we form portfolios not only based on past performance but additionally on the fund characteristics identified as "persistence-enhancing" factors in the probit regressions. The performance of these sorted portfolios is then tested out-of-sample in the next period. After each tracking period the sorting is repeated. We calculate the alpha of each fund within a portfolio and apply equal weights. A similar portfolio approach has been used in the mutual fund literature by Hendricks et al. (1993) and Carhart (1997).

The first fund characteristic we use as explanatory variable in the probit regression is the Strategy Distinctiveness Index (SDI) as originally suggested by Wang and Zheng (2008), defined as $\left(1-R^{2}\right)$, using the r-square of a fund's 24 monthly historical returns regressed against the equally-weighted strategy index. SDI measures the percentage of total variance in fund returns that cannot be explained by the returns of its peers. The higher the SDI, the more distinctive, and presumably the more successful, is the fund's investment strategy. If hedge funds within a certain strategy exhibit more dispersion than within other strategies, the funds in our sample with a high SDI value may have a disproportional tilt towards this strategy. Therefore, the performance difference associated with SDI may be driven rather by the funds' strategy than their distinctiveness. Hence, we standardize the SDI within each strategy by subtracting the average SDI within the same strategy and dividing by the crosssectional standard deviation in SDI within this strategy. Wang and Zheng (2008) show that this index is a good predictor for the future performance of a fund.

In various robustness tests, we use alternative versions of SDI. To mitigate the well known problem of erroneous strategy classifications in the commercial hedge fund databases due to self-reporting by the funds, we alternatively calculate SDI against the highest correlated 
strategy index instead of the self-declared strategy index. Following Titman and Tiu (2008), who argue that better informed hedge funds choose less exposure to systematic factor risk, we alternatively calculate SDI against the stepwise regression model. Furthermore, we alternatively define SDI as the r-square from a regression of the funds' returns on the returns of the funds' self-declared strategy index and the returns of an index of all hedge funds in our sample. Finally, we also use the alternative SDI measure proposed by Sun et al. (2009), a revised version of Wang and Zheng (2008), which is defined as one minus the correlation of the individual hedge funds' returns with the average returns of their peer funds with the same strategy classification. This SDI ranges between 0 and 2 in theory.

The second fund characteristic we use is lagged fund flows. Fung et al. (2008) investigate the relation between alpha and lagged fund flows on an individual fund of fund level and conclude that funds which generated a statistically significant alpha in the past and experience above-median capital inflows, are more likely to lose their ability to generate a statistically significant alpha in the future. ${ }^{12}$ To calculate lagged fund flows, we follow a similar approach as Naik et al. (2007), Fung et al. (2008), and Titman and Tiu (2008) and compile the annual relative net fund flows for each fund-month observation. If a fund does not report the assets under management for a particular month, we interpolate the figure linearly over time. When the first or the last entry for assets under management is missing, we write the first or last entry backward and forward. Fund flows into fund $i$ in month $t\left(F_{i, t}\right)$ are calculated as a function of the current and the lagged assets under management $\left(A u M_{i, t}\right)$ and the monthly returns $\left(r_{i, t}\right)$ :

$$
F_{i, t}=A u M_{i, t}-A u M_{i, t-1}\left(1+r_{i, t}\right)
$$

Capital inflows are treated as if they were received at the end of each month. For the calculation of the annual relative net fund flows $\left(F F_{i, t}^{r e l}\right)$, the monthly absolute fund flows are ag-

\footnotetext{
${ }^{12}$ Ammann et al. (2010) confirm these findings using single hedge funds over the same time period as Fung et al. (2008) but find contradicting evidence when using a longer sample period.
} 
gregated and calculated in relation to the assets under management of each fund $\left(A u M_{(i, t-12)}\right)$ one year earlier:

$$
F F_{i, t}^{r e l}=\frac{\sum_{t=-1}^{-12} F_{i, t}}{A u M_{i, t-12}}
$$

Finally, we winsorize the relative yearly fund flows at the $1 \%$ tails to account for extreme observations.

Further, we include a number of fund characteristics in our probit regressions that are related to a fund's liquidity. Aragon (2007) finds that the positive and significant alpha of hedge funds disappears after controlling for lockup restrictions, notice period length, and minimum investment size. He therefore interprets the abnormal average return as a liquidity premium. The liquidity-related variables we include in our regressions are the natural logarithm of the notice period length (in days), the natural logarithm of the redemption period length (in days $)^{13}$, and a dummy variable whether the fund is closed to new investments. ${ }^{14}$ Finally, we include fund size as measured by the natural logarithm of assets under management and fund age as measured by the natural logarithm of the months a fund existed (or the number of months a fund reported its returns in case the inception date is unknown). As it is common in the literature, we use fund age also as proxy for manager experience (e.g., Boyson, 2010). In general, it is assumed in the hedge fund literature that the same manager stays with a fund over its entire fund life and Boyson (2010) provides empirical support for this conjecture.

\footnotetext{
${ }^{13}$ If a fund labels its redemption frequency to be 'other' than the categories provided by the databases (which end at triennial), we assign a value of 1,048 days (four years in terms of trading days).

${ }^{14}$ In unreported robustness tests, we additionally use the natural logarithm of the length of the lockup period and the length of the subscription period. However, these variables are estimated to be insignificant in most specifications and add very little explanatory power to the models.
} 


\section{Empirical analysis}

\subsection{Fund characteristics and performance persistence}

In Table 2, we investigate the relationship between various fund characteristics and the performance persistence of single hedge funds. The dependent variable is a dummy variable which is equal to one if a fund is a winner (loser) fund in two consecutive, non-overlapping time periods of 12 months (Columns 1 to 3), 24 months (Columns 4 to 6), and 36 months (Columns 7 to 9). Winner (loser) funds are defined as funds which exhibit an above-median (below-median) alpha based on the stepwise regression model. We use three alternative specifications of the dependent variable, the first summarizing performance persistence of both winners and losers (Columns 1, 4, and 7), the second only indicating winner persistence (Columns 2, 5, and 8), and the third measuring loser persistence only (Columns 3, 6, and 9). As the dependent variable is binary (a value of one indicates performance persistence and a value of zero no persistence), we estimate probit regressions. ${ }^{15}$ In all regressions we include time and strategy fixed effects and the full set of control variables including the strategy distinctiveness index (SDI), fund size $(\operatorname{Ln}(\mathrm{AuM}))$, relative fund flows (Relative fund flows), fund age $(\operatorname{Ln}($ fund age in months)), the length of the notice period $(\operatorname{Ln}($ notice days $))$, the length of the redemption period ( $\operatorname{Ln}($ redemption days)), a dummy variable whether the fund is closed to new investments (Closed to investment), and management (Management fee) and incentive fees (Incentive fee).

The results on 12-month persistence in Columns 1 to 3 of Table 2 show that the coefficients on all explanatory variables exhibit the opposite sign for winner (Column 2) and loser persistence (Column 3). Moreover, the coefficients on all explanatory variables are significant at the $1 \%$ level for both winner and loser persistence. As a consequence of the inverse signs for winners and losers, the significance of the coefficients is substantially reduced in Column 1, where winner and loser persistence is investigated jointly. Hence, while the same factors are

\footnotetext{
${ }^{15}$ In unreported robustness tests, we alternatively use linear panel regressions including time and strategy fixed effects with cluster robust standard errors (where the clustering is at the single hedge fund level) and Fama and MacBeth (1973) regressions with heteroscedasticity and autocorrelation consistent standard errors. However, the results based on all these alternative estimation procedures are very similar and remain qualitatively unchanged.
} 
significantly related to both winner and loser performance, the direction of this correlation is diametrically opposed for winners and losers. Most importantly, we find a positive and highly significant coefficient on SDI for winner persistence indicating that funds with a high SDI, i.e., funds with skilled managers following proprietary trading strategies, are more likely to be persistent winner funds. This finding is consistent with Wang and Zheng (2008). In contrast, the coefficient on SDI is negative and highly significant for loser persistence indicating that funds with a high SDI are substantially less likely to be persistent underperformers as compared to funds with a low SDI. Moreover, winner persistence is significantly positively related to fund size, relative fund flows, the fund illiquidity as measured by the length of the notice and redemption periods, and management and incentive fees. Further, the negative coefficient on $\operatorname{Ln}(\mathrm{AuM})$ indicates that smaller funds are more likely to be persistent winners. This finding is consistent with a recent study by Aggarwal and Jorion (2010) who show that young and emerging funds exhibit strong performance persistence. Finally, funds closed to new investments are more likely to be persistent winners.

For the longer time horizons of 24 (Columns 4 to 6) and 36 months (Columns 7 to 9), we find qualitatively similar results with no change in signs or the level of significance for both winner and loser persistence (with two exceptions: the coefficients on the incentive fee variable turn insignificant in Columns 5 and 8). However, the magnitude of the t-values somewhat decreases in the length of the time period over which persistence is measured but all coefficients remain significant at the $1 \%$ level. In contrast and as expected, the results on the joint persistence of winners and losers in Columns 1, 4, and 7 change - depending on the relative size and significance of the coefficients in the respective winner- and loser-regressions.

We perform a number of robustness tests on these results. First, we extend the set of nine fund characteristics and additionally include a dummy variable for whether the fund management is personally invested in the fund and the funds' average leverage ratio. Both these variables show relatively poor coverage in both the TASS and CISDM databases and reduce the sample size from between 44,300 and 111,646 fund-month observations as reported in Table 2 to between 14,188 and 41,834 fund-month observations, a decrease by roughly two thirds. The coefficient on the dummy variable for whether fund management is personally 
invested in the fund is always positive and significant for winner persistence and negative and significant for loser persistence. The coefficient on the leverage variable is always negative but significant only for winner persistence over the 12- and 36-month horizons. ${ }^{16}$ Second, we reestimate all regressions by replacing the dependent variable and using the $\mathrm{FH}$ alpha instead of the SW alpha when assessing performance persistence. The results are very similar to those reported in Table 2 and therefore not reported in a table for space reasons. Third, we use more restrictive alpha quantiles than the median to classify funds as winners and losers, including the $30 \% / 70 \%$ and the $20 \%$ / $80 \%$ quintiles. Again we find the results to remain qualitatively unchanged with the exception of the negative coefficient on SDI for loser persistence which turns insignificant for the 36-month horizon. Fourth, we use alternative versions of SDI as explained in Section 2.3. The results remain qualitatively identical for all four alternative versions of SDI and are therefore not reported for space reasons. Finally, we investigate the performance persistence of raw returns instead of alphas. Again the results remain virtually unchanged with one important exception: the coefficient on SDI switches signs and is now negative and significant for winner persistence and positive and significant for loser persistence. Hence, the results of the probit regressions on raw returns suggest that funds with a low SDI have persistently high raw returns while the results in Table 2 show the these low SDI funds have persistently low alphas. Hence, funds with a low SDI seem to load on large amounts of systematic risk. This is exactly what the SDI attempts to measure: Funds with a high SDI are expected to follow proprietary trading strategies and have less systematic risk while low SDI funds are expected to herd and thereby carry more systematic risk.

\subsection{Fund characteristics and alpha}

In this section, we investigate the relation between alpha and the same fund characteristics included in the analysis of alpha persistence reported in Table 2. We estimate panel regressions of hedge fund alpha on the nine fund characteristics, or sub-sets thereof, and include time

\footnotetext{
${ }^{16}$ For space reasons, we do not report these results in a table. They are, however, available from the authors upon request.
} 
and strategy fixed effects. To account for clustering at the fund-level, i.e., the dependence of observations on one specific fund, we use the cluster-robust variant of the Huber-White sandwich estimator. The results are reported in Table 3. In Columns 1, 3, and 5, the dependent variable is an alpha based on a stepwise regression approach and in Columns 2, 4, and 6, the dependent variable is an alpha based on the Fung and Hsieh (2004) seven-factor model.

The results from estimating regressions including the full set of nine fund characteristics are reported in Columns 1 and 2. Most importantly, the coefficient on SDI is positive and significant at the $1 \%$ level in both specifications. This finding is consistent with Wang and Zheng (2008) and suggests that funds with skilled managers pursuing unique trading strategies exhibit higher alphas than funds with presumably less skilled managers following publicly known trading strategies. The positive and significant coefficient on $\operatorname{Ln}(\mathrm{AuM})$ indicates that larger funds exhibit higher alphas. This finding is consistent with Teo (2009) for example. Relative fund flows over the last year are positively related to hedge fund alpha. This finding is consistent with Ammann et al. (2010) but contradicts Fung et al. (2008). Consistent with Aragon (2007), the two variables related to fund liquidity, i.e., the length of the notice period and the length of the redemption period, are both estimated to be positive and significant (with the exception of $\operatorname{Ln}($ redemption days) which is not significant in Column 2). Hence, we find some evidence of a liquidity premium associated with hedge fund investing. Finally, the coefficient on fund age, the dummy variable whether the fund is closed to new investments, as well as management and incentive fees are all insignificant.

In unreported tests, we additionally include the dummy variable for whether the fund management is personally invested in the fund and the funds' average leverage ratio in the regression equations reported in the first two columns of Table 3. However, the coefficients on both of these variables are insignificant in both specifications while the sample size is substantially reduced to 90,802 observations when only the dummy variable for the fund management's investment is included, 87,376 observations when only leverage is added, and 56,710 when both variables are included. Moreover, none of these two variables is selected in the stepwise approach explained below. Therefore, we do not report the results from these 
extended regression specifications for space reasons.

In Columns 3 and 4, we use a similar forward stepwise regression approach as for the factor choice when calculating the SW alpha (see Section 2.2). The three factors chosen out of a pool of 15 factors are the standard SDI (i.e., calculated against the self-declared strategy), fund size, and relative fund flows. ${ }^{17}$ The results are consistent with those in Columns 1 and 2 and show that funds with a high SDI, larger funds, and funds with high relative fund flows have higher alphas on average. All coefficients are significant at the $1 \%$ level.

The first factor that was not chosen by the forward stepwise regression approach, or the last one to be dropped by a backward stepwise regression approach, was the natural logarithm of the sum of the notice days and redemption period. Hence, as a robustness check, we additionally include this variable besides the three variables chosen by the stepwise regression approach. While the coefficients on SDI, fund size, and relative fund flows all remain positive and significant at the $1 \%$ level, the coefficient on the combined notice and redemption period variables is also positive and significant at the $1 \%$ level in both specifications. Hence, we confirm the finding of an illiquidity premium. Moreover, and consistent with Aragon (2007), we show that the positive and significant monthly alphas of $0.49 \%$ and $0.51 \%$ reported in Columns 3 and 4, turn negative in Columns 5 and 6 when the liquidity-based control variables are included in the regression. After controlling for these trading restrictions, fund performance is reduced by $0.84 \%$ and $1.25 \%$ and insignificant or even negative and significant. In Columns 7 and 8 , we replicate the results in Columns 5 and 6 while additionally controlling for the effect of performance persistence by including an alpha lagged by 24 months. The coefficients on all explanatory variables remain qualitatively unchanged as compared to Columns 5 and 6 while the coefficients on alpha are positive in both specifications (but significant only in Column 7).

\footnotetext{
${ }^{17}$ The 15 factors to choose from are: the SDI against the self-declared strategy (and the four alternative definitions of SDI), relative fund flows, fund size, fund age, length of the notice period, length of the redemption period, a dummy variable whether the fund is closed to new investments, management fees, incentive fees, a dummy variable for whether the fund management is personally invested in the fund, and leverage (and alternatively, instead of the length of the notice period and the length of the redemption period, the sum of these two). To mitigate the problem of multicollinearity of the independent variables, only one of the three alternative SDIs and only either the sum of the lengths of the notice and redemption periods or one (or both) of its constituents are allowed to be selected.
} 


\subsection{Forming persistent portfolios}

In this section, we investigate whether the factors that have been identified to enhance hedge fund performance persistence (and hedge fund alpha) in Section 3.1 (Section 3.2) allow the construction of hedge fund portfolios that persistently outperform other hedge fund portfolios. We proceed by extending the traditional portfolio-approach to assess performance persistence, as for example used in Hendricks et al. (1993) and Carhart (1997), by forming portfolios not only based on past performance but additionally on the fund characteristics identified as "persistence-enhancing" factors in the probit regressions of Section 3.1. The performance of these sorted portfolios is then tested out-of-sample over the subsequent period of 6 to 36 months. After each tracking period the sorting is repeated. ${ }^{18}$

In Table 4, we first sort the hedge funds into five sub-portfolios based on the funds' historical 6-month, 12-month, 24-month, and 36-month alphas. Next, the funds within each of these five portfolios are sorted further based on the SDI over the previous 24 months: We divide each of the five alpha-sorted portfolios into two sub-portfolios, one including those hedge funds with an above- and one including those with a below-median SDI. This sorting algorithm ensures an even distribution of the number of hedge funds across portfolios and prevents portfolios from including very few or no funds at all. However, the selection of funds within each portfolio is dependent on the sorting pattern. ${ }^{19}$ After each tracking period the sorting is repeated and the portfolio rebalanced. For investigating 6-month performance persistence, the portfolios are rebalanced biannually, annually for 12-month persistence, biennially for 24month persistence, and triannually for 36-month persistence. The performance of these sorted portfolios, as measured by the FH and SW alpha, is then tested out-of-sample in the next non-overlapping 6-month, 12-month, 24-month, and 36-month period. Panel A reports the results from the analysis of 6 -month performance persistence (i.e., sorting based on 6 -month historical alpha, biannual rebalancing, and test of 6-month out-of-sample performance), Panel $\mathrm{B}, \mathrm{C}$, and $\mathrm{D}$ from the analyses of 12-month, 24-month, and 36-month persistence.

\footnotetext{
${ }^{18}$ If hedge funds within a portfolio disappear from the sample, we estimate their alpha for the time period until defunct.

${ }^{19}$ Therefore, in a robustness check, we will reverse the order of this sorting procedure.
} 
The results on 6-month performance persistence in Panel A of Table 4 show that portfolio alphas increase monotonically in both the historical alpha and the SDI. The differences between the portfolios with the highest historical alpha (alpha 5) and the portfolios with the lowest historical alpha (alpha 1) amount to between $2.46 \%$ and $3.03 \%$ monthly alpha and are all significant at the $1 \%$ level for both the SW alpha and the FH alpha as well as the "SDI high" and "SDI low" sub-portfolios. However, the difference between the high- and low-SDI portfolios is insignificant with two exceptions (the alpha 5 and alpha 2 sub-portfolios when using the SW alpha). In the first and fifth columns ('alpha only'), we use a one-way portfolio sort based on historical alpha only and in the last column based on SDI only. Consistent with our expectations and the results in Table 2, we find significantly higher returns for the portfolio including hedge funds with high SDI as compared to the portfolio including low-SDI funds. The difference amounts to $0.35 \%$ monthly alpha and is significant at the $1 \%$ level. Moreover, the portfolio alphas increase monotonically in the historical alpha providing strong evidence of performance persistence over a 6-month horizon. The difference in monthly SW (FH) alpha between the portfolio with the highest historical alpha and the portfolio with the lowest historical alpha is $2.80 \%(2.66 \%)$ and significant at the $1 \%$ level. Further, consistent with Ammann et al. (2010) and Titman and Tiu (2008), the results in Panel A show that FH alphas are in general higher as compared to the SW alphas.

To assess whether using two-way sorts based on historical alphas and the SDI as compared to using one-way sorts based on historical alphas only, we need to compare the alphas of the high-alpha/high-SDI portfolios to those of the low-alpha/low-SDI portfolios. In Panel A of Table 4, the resulting return differences are $3.10 \%$ and $2.77 \%$ for the SW and the FH alpha, respectively. The "pure" performance persistence based on one-way alpha sorts is $2.80 \%$ and $2.66 \%$ as indicated in the first (SW alpha) and fifth (FH alpha) columns of the table. Hence, additionally using SDI as a second sorting criterion increases alphas by $0.30 \%(0.11 \%)$ per month or $3.60 \%(1.32 \%)$ per annum. Hence, while a one-way sorting procedure based on historical SW and FH alpha already generates a very high difference in alpha of monthly $2.88 \%$ and $2.66 \%$ between the high- and low-alpha portfolios, an additional sorting based on the SDI allows to further increase this difference in alpha. 
The average adjusted r-squares of all funds within a portfolio are reported in square brackets for each of the five alpha-sorted portfolios as well as for the 10 alpha and SDI two-way sorted portfolios. ${ }^{20}$ The r-square values are remarkably constant across the different alphasorted portfolios but show large differences between the SDI-sorted portfolios. Specifically, the r-squares of the low-SDI portfolios are substantially higher than those of the high-SDI portfolios. This finding is expected as the SDI is defined as one minus the r-square of a fund's 24 monthly historical returns regressed against an equally-weighted strategy index. If the strategy index is positively correlated to the majority of risk factors included in the two alternative factor models, which can be expected (and is observed in unreported tests), a high SDI is associated with a lower r-square in the factor model regressions by construction. In fact, this result holds for both alternative factor models and all four rebalancing horizons reported in Table 4.

The results on the 12-month performance persistence in Panel B show a similar pattern. Again we find a monotonic increase of the portfolio alphas in the historical alpha. Moreover, the alpha of the high-SDI portfolio is always higher than the alpha of the corresponding low-SDI portfolio. Again, the differences between the high-alpha and low-alpha portfolios are all significant at the $1 \%$ level while the differences between the high- and low-SDI portfolios are insignificant with one exception (the alpha 5 sub-portfolio based on the SW alpha). As compared to the results on the 6-month performance persistence in Panel A, the differences in alphas between high- and low-alpha as well as between high- and low-SDI portfolios are reduced only slightly. When using one-way sorts based on either historical alpha or the SDI only, we still find significantly higher returns for the portfolio including hedge funds with high SDI as compared to the portfolio including low-SDI funds and for the high-alpha as compared to the low-alpha portfolios. The differences are significant at the $5 \%$ and $1 \%$ level, respectively. Most importantly, we find a two-way sort based on both alpha and SDI to further increase performance persistence and even more so than over the 6-month horizon. Specifically, the difference in alpha increases from $2.29 \%(2.32 \%)$ between the two extreme

\footnotetext{
${ }^{20}$ Note that the average adjusted r-squares reported in Table 4 are substantially lower than those mentioned at the end of Section 2.2 as the r-squares in Table 4 are average values based on the individual funds' r-squares while the r-squares in Section 2.2 are calculated at the index level.
} 
portfolios, when sorting is based on the SW alpha (FH alpha) only, to $2.62 \%$ (2.39\%) when sorting is based on both SW alpha (FH alpha) and the SDI. This is an increase in alpha of $0.33 \%(0.07 \%)$ per month or $3.96 \%(0.84 \%)$ p.a.

The results on 24-month performance persistence are reported in Panel $\mathrm{C}$ and show that we find performance persistence even over a two-year period. We still find portfolio alphas to increase monotonically in both the historical alpha and the SDI with few exceptions (the FH alpha of the low-SDI sub-portfolios are larger than the FH alpha of the high-SDI sub-portfolios within the alpha 1 and alpha 2 portfolios and the SW alpha of the low-SDI sub-portfolio is larger than the SW alpha of the high-SDI sub-portfolio within the alpha 1 portfolio). The results from a one-way sort based on whether the SDI is above or below the median shows that the alpha of the high-SDI portfolio is larger and significant at the $1 \%$ level as compared to the insignificant alpha of the low-SDI portfolio. The difference between the alpha of the highand the alpha of the low-SDI portfolios, however, is insignificant. In contrast, the differences in alpha between the high- and low-alpha portfolios amount to a monthly $1.61 \%$ (SW alpha) and $1.81 \%$ (FH alpha) and are significant at the 1\% level. The alpha differences between the high-alpha/high-SDI portfolios and the low-alpha/low-SDI portfolios are $1.80 \%$ and $1.88 \%$ for the SW and FH alpha, respectively. Hence, the valued-added by additionally using the SDI as a second sorting criterion amounts to $0.19 \%(0.07 \%)$ monthly or $2.28 \%(0.84 \%)$ yearly for the SW (FH) alpha sorts.

The results on 36-month performance persistence in Panel D show that there is even economically and statistically significant performance persistence over a three-year period. Portfolio alphas increase almost monotonically in the historical alpha and the return difference between the high-alpha and low-alpha portfolios amount to $0.99 \%$ and $1.10 \%$ for the SW and FH alpha, respectively. However, SDI does no longer positively contribute to portfolio returns. The differences in portfolio returns between the high-SDI and low-SDI portfolios are often very small and sometimes even negative. In fact, the alpha differences between the highalpha/high-SDI portfolios and the low-alpha/low-SDI portfolios of $0.92 \%$ (SW alpha) and $0.86 \%$ (FH alpha) are smaller than alpha differences resulting from one-way alpha sorted portfolios. Hence, additionally using the SDI as a second sorting criterion does not improve 
but deteriorate performance persistence.

We perform a number of robustness checks on these results. First, we reverse the order of the sorting procedure and start by sorting the hedge funds into two portfolios based on whether their SDI over the previous 24 months is above or below the median SDI. Then, we build five sub-portfolios within each of these two portfolios based on the historical 12-month SW alpha. The results for the 12-month horizon are reported in the first three columns of Table 5. Most importantly, the results show that the portfolio alphas still monotonically increase in both the historical alpha and the SDI. Moreover, the differences in SW alpha between the portfolios with the highest historical alpha (alpha 5) and the portfolios with the lowest historical alpha (alpha 1) of $2.44 \%$ and $2.05 \%$ remain significant at the $1 \%$ level. In addition, the differences in alphas between the high- and low-SDI portfolios somewhat increases in magnitude (and significance for the alpha 3 and alpha 4 portfolios). The alpha differences between the high-alpha/high-SDI portfolios and the low-alpha/low-SDI portfolios is $2.69 \%$ per month. Hence, the value added from using the two-way sort is even larger here as compared to Panel B of Table 4. As a second robustness test, we first sort the hedge funds into three SDI portfolios according to the SDI tercile and then into five portfolios according to the historical FH alpha. The results are reported in the fourth to seventh column and show a monotonic increase of portfolio alphas in the historical alpha as well as in SDI (with the exception of the alpha 1 sub-portfolio). The differences between the portfolios with the highest historical alpha and the portfolios with the lowest historical alpha of $2.36 \%, 1.52 \%$, and $2.10 \%$ are all significant at the $1 \%$ level. In contrast, the differences between the high-SDI and low-SDI portfolios are all insignificant. The alpha differences between the high-alpha/highSDI portfolios and the low-alpha/low-SDI portfolios is $2.50 \%$ per month. Hence, the benefit from using the SDI as a second sorting criterion is somewhat reduced as compared to the previous specifications. As a third robustness test, we first sort the hedge funds into decile portfolios based on historical alpha and then into two SDI-portfolios based on whether the SDI is above or below the median of the sub-portfolio. Again we find portfolio alphas to increase monotonically in both historical alphas and SDI. As in Tables 4 and 5, the difference in portfolio alpha resulting from additionally sorting based on the SDI is strongest for the 
highest-alpha decile. The results based on these alpha-decile portfolios are not reported for space reasons. ${ }^{21}$ As a fourth robustness test, we repeat the analyses in Table 4 but use the t-values of the alpha instead of the alpha as the second sorting criterion.

Wang and Zheng (2008) propose two alternative hypotheses related to the relation between SDI and alpha. The first is the "skill hypothesis" which claims that managers with a high SDI have great new ideas and superior investment skills resulting in unique, proprietary trading strategies, while less skilled managers are more likely to herd. This hypothesis suggests a positive relation between SDI and fund performance. The "gaming hypothesis" states that funds may appear to deviate from their peers due to a potential conflict of interests between fund managers and investors, triggered by high-watermarks and other option-like characteristics of their compensation packages. These compensation packages might provide incentives for managers to take idiosyncratic risk in order to increase the chance of having extreme performance. Our results so far provide support for the skill hypothesis as we find a positive relation between SDI and alpha and between SDI and positive performance persistence. To further investigate the gaming hypothesis, we investigate the annual attrition rates of the portfolios reported in the first two columns of Table 5 as well as the attrition rates of portfolios that are either exclusively sorted based on the historical 12-month SW alpha or the SDI. The results are reported in the last four columns of Table 5. The attrition rate decreases monotonically in the historical SW alpha and increases in SDI. Hence, the portfolio with the highest historical alpha and an SDI below the median exhibits the lowest attrition rate of $7.1 \%$ while the portfolio with the lowest historical alpha and an above-median SDI exhibits the highest attrition rate of $20.0 \%$ - an increase by a factor of roughly 2.8 . The finding of a higher attrition rate for funds with a high SDI is consistent with the results in Wang and Zheng (2008) as well as with the gaming hypothesis.

Although our sample includes both live and dead funds, there is no return data available after funds stop reporting. If some of the funds dropping out of the sample continue to operate and the (unreported) performance is substantially different from the performance of

\footnotetext{
${ }^{21}$ We performed all these robustness tests also for the 6-month, 24-month, and 36-month horizon and found the results to remain robust as well.
} 
funds that do report, the portfolio returns which are only based on reporting funds would be biased. As the majority of funds that stop reporting to TASS do so because of a liquidation of the fund (e.g., Getmansky et al., 2004b) and delisting returns have been estimated to be significantly lower than reported returns (Hodder et al., 2009), a higher attrition rate is likely to indicate an upward bias in returns as the lower delisting returns are not available. To investigate whether the differences in portfolio returns in our sample can be (partly) explained by differences in delisting returns of funds dropping out of our sample, we would need return data for funds after dropping out of our sample which is naturally not available. Hence, we perform the same back-of-envelope calculations as in Wang and Zheng (2008) to investigate how low the alpha of defunct funds can be in the first year after dropping out of our sample in order to eliminate the alpha difference between the low and the high SDI portfolios. For the two portfolios constructed exclusively based on the funds' SDI (i.e., whether the SDI is above or below the median) the attrition rates are 13.2\% (high SDI portfolio) and $10.6 \%$ (low SDI portfolio), respectively. This translates into an average annualized alpha of the disappearing funds that can be as low as $-126.3 \%$ to make the return differences between the two portfolios to disappear. ${ }^{22,23}$ In addition, the decrease in the attrition rate with increasing historical alphas does even enhance the alpha persistence we find in our sample. For example, for the two-way sorted portfolios in Panel B of Table 4, the attrition rate for the high-SDI and high-alpha portfolio is $10.1 \%$ and for the low-SDI and low-alpha portfolio $15.1 \%$, respectively. Hence, accounting for the delisting returns of the hedge funds disappearing from the sample would presumably even increase the return differences between the two portfolios.

To account for the possible effect of outliers on our portfolio returns, we alternatively report portfolio median returns. The results in Panel A of Table 6 show that for a 12-month

\footnotetext{
${ }^{22}$ Wang and Zheng (2008) perform their back-of-envelope calculations for five portfolios sorted based on the funds' SDI only. If we repeat their analysis, we find annual attrition rates of $13.7 \%$ for the highest-SDI portfolio and $9.9 \%$ for the lowest-SDI portfolio. The corresponding monthly alphas are $0.59 \%$ and $0.09 \%$, respectively. This translates in an average annual alpha of below $-147.6 \%$ for the defunct funds to eliminate the difference in alphas between the two portfolios. For comparison, Wang and Zheng (2008) report a value $-101.8 \%$.

${ }^{23}$ In their recent study, Hodder et al. (2009) use estimated portfolio holdings for funds of hedge funds with reported returns to back out maximum likelihood estimates for hedge funds' delisting returns. Across all delisting hedge funds, they estimate a mean delisting return of $-1.86 \%$ which compares with a mean monthly return for all hedge funds in their sample of $1.01 \%$.
} 
horizon our results still hold based on medians while the median returns of the extreme portfolios (i.e., the alpha 1 and alpha 5 portfolios) are somewhat reduced in absolute terms, i.e. less negative for the alpha 1 portfolio and less positive for the alpha 5 portfolio. Alpha persistence amounts to a sizable $1.84 \%$ (1.90\%) per month for the SW (FH) alpha and the alpha contribution from additionally sorting for SDI is $0.43 \%(0.08 \%)$ per month (or $5.16 \%$ (0.96\%) p.a.). Over the 24 -month horizon, alpha persistence is reduced to $1.15 \%(1.40 \%)$ for the SW (FH) alpha and the contribution of the SDI sort to $0.04 \%(0.01 \%)$ per month. For the 36-month time horizon, alpha persistence is reduced to $0.85 \%(0.92 \%)$ per month for the SW (FH) alpha while the effect of additionally sorting for SDI disappears altogether. The results on the 24- and 36-month horizons are not reported for space reasons.

Kosowski et al. (2006) and Kosowski et al. (2007) argue that ranking funds by the tstatistic of their alpha instead of alpha controls for differences in risk-taking across funds. Moreover, they present a number of statistical arguments to justify that the t-statistic of alpha is preferable to alpha. Hence, as a further robustness check, we sort our portfolios based on the t-statistics of the alpha and SDI. The results on the 12-month horizon in Panel B show that using the t-statistic of alpha instead of alpha again does not qualitatively change the results. Alpha significance is somewhat lower as compared to Panel A and amounts to $1.59 \%(1.60 \%)$ for the SW (FH) alpha. and the alpha contribution from additionally sorting for SDI is $0.09 \%$ (0.01\%) per month (or $1.08 \%$ (0.12\%) p.a.). As in Panel A, alpha persistence and the contribution of additionally sorting for SDI decreases for longer time horizons and the latter disappears altogether over a 36-month horizon. The results on the 24- and 36-month horizons are not reported for space reasons.

In Table 7, we investigate the performance persistence resulting from a sorting based on raw returns as well as the persistence in raw returns. We start by using raw returns instead of alphas as a first sorting criterion (and again the SDI as a second sorting criterion) to build portfolios and then calculate the average monthly alphas of these portfolios. The first six columns in Panels A, B, C, and D report the results on 6-month, 12-month, 24-month, and 36-month persistence based on the SW and the FH alpha, respectively. As in Tables 4 and 5 , the results show that portfolio alphas increase monotonically in both the historical returns 
and the SDI for horizons up to 24 months with two exceptions (over a 24-month horizon, both the SW and the FH alphas are higher for the low-SDI than the high-SDI portfolios in the lowest return sub-portfolios). The differences in alpha between the high-return (return 5) and the low-return portfolios (return 1) are all significant at the $1 \%$ level. Over a 36-month horizon, alphas still increase almost monotonically in historical returns and the differences in alpha between the high-return (return 5) and the low-return portfolios (return 1) are all significant at the $5 \%$ level or better. However, there is no clear pattern in alphas between highand low-SDI portfolios anymore. In contrast to Tables 4 and 5, the difference between the high-SDI and low-SDI portfolios are all significant at the $10 \%$ level or better for the 6 - and 12month horizons and the SW alpha but mostly insignificant otherwise. In the seventh to ninth columns of Table 7, we investgiate the persistence in raw returns and report the portfolios' annual effective cumulative raw returns. In Panel A, we find the portfolio raw returns to increase monotonically in both the historical returns and the SDI. The differences in annual returns between the high-return (return 5) and the low-return portfolios (return 1) amount to $11.09 \%$ and $9.41 \%$ and are significant at the $1 \%$ and $10 \%$ level for the high- and the low-SDI portfolios, respectively. In contrast, the differences between the high- and low-SDI portfolios are all insignificant. Over the 12-month and 24-month time horizons, we still find evidence of persistence in raw returns in the high-return portfolios. However, the differences in annual returns between the high-return (return 5) and the low-return portfolios (return 1) are all insignificant. Moreover, the relation between SDI and portfolio returns becomes ambiguous. Over the 36-month horizon (Panel D), we find no evidence of performance persistence in raw returns. The last two columns of Table 7 report the returns of one-way sorted portfolios based on their historical returns and their SDI, respectively. For time horizons of up to 24 months, we find a positive return contribution from using a two-way sort based on both historical returns and the SDI as compared to using one-way sorts based on historical returns only. The differences in portfolio returns between the high-return / high-SDI portfolio and the low-return / low-SDI portfolio are $11.12 \%, 5.26 \%$, and $6.94 \%$ p.a. for the 6 -month, 12 -month, and 24-month time horizons, respectively. The corresponding values from the one-way sorted portfolios based on historical returns are $10.25 \%, 4.06 \%$, and $5.17 \%$, respectively. 
We alternatively also tested two-way portfolio sorts based on alphas and other variables than the SDI. As SDI turned out to be the variable with the highest explanatory power for alpha persistence (Table 2) as well as alphas (Table 3), we started by using the SDI as the second sorting criterion besides historical alpha. We repeated the complete set of analyses and used relative fund flows, fund size, as well as the measures of illiquidity as second sorting criterion besides historical alpha. While the effect resulting from using the SDI as a second sorting criterion turned out to be substantial and economically meaningful, the effect resulting from using these alternative fund characteristics as second sorting criterion is relatively small and not robust. In fact, we found none of these fund characteristics to systematically help in improving the alpha (or return) persistence. Hence the results from these alternative two-way sorts are not reported in a table for space reasons.

We also repeated our main analyses on the strategy level and found alpha persistence and a positive contribution to portfolio alphas resulting from an additional sorting based on the SDI for all nine tested strategies. ${ }^{24}$ Over a 12-month horizon, alpha persistence is highest for the strategies Emerging Markets, Equity Market Neutral, Event Driven, and Managed Futures. The difference in portfolio alphas based on SDI-sorting is highest for the strategy Managed Futures and Emerging Markets. The difference in alpha between the high-alpha / high-SDI portfolio and the low-alpha / low-SDI portfolio is largest for the strategy Managed Futures. For space reasons, we do not report the results on the strategy level. ${ }^{25}$

One potential concern with our results may be that they are influenced by the desmoothing of returns as described in Section 2.1. In fact, the procedure suggested by Getmansky et al. (2004a) to desmooth the returns reported in hedge fund databases may increase persistence by picking up information contained in previous returns in the $\mathrm{MA}(2)$ estimations. Therefore, we repeat all analyses based on reported instead of desmoothed returns. We find the results to remain basically unchanged as compared to the results reported in Tables 4 to 7 . Hence, for space reasons we do not report any of these results in a table. ${ }^{26}$

\footnotetext{
${ }^{24}$ Due to the very small sample size, we excluded the strategy Dedicated Short Bias from this analysis.

${ }^{25}$ The full set of results, however, is available from the authors upon request.

${ }^{26}$ The results are available from the authors upon request.
} 
Finally, we investigate whether (and how) the recent credit crisis of 2008 affects our results. We do this based on three alternative approaches. In the first approach, we investigate whether our results hold during the crisis period based on TASS data from September 2007 to June $2009 .{ }^{27}$ As in Table 4, we then sort all 1,164 hedge funds in this sample into five quintileportfolios based on their historical performance over the 12-month period from September 2007 to August 2008. We then split each of these five portfolios into two sub-portfolios based on their SDI and calculate the performance of these 10 portfolios as well as the five alphasorted portfolios, and the two SDI-sorted portfolios over the 10-month period from September 2008 to June 2009. In September 2008, Lehman's filing for Chapter 11 bankruptcy protection ushered in an extended period of the worst deteriorations in stock returns during the financial crisis. The results for both the SW and FH alphas are reported in Table 8. Most importantly, the results show that the alpha 5 portfolios always exhibit the highest alpha and the alpha 1 portfolios the lowest alphas. The differences in alphas between the alpha 5 and alpha 1 portfolios are all significant at the $1 \%$ level and indicate monthly return differences of between $1.35 \%$ and $1.73 \%$. However, both the SW and the FH alphas show no ordering according to their historical performance across alpha portfolios 2 to 4 . A comparison of the highalpha/high-SDI portfolios' alphas with the alphas of the low-alpha/low-SDI portfolios shows that an additional sorting based on SDI does not further improve alpha persistence. In fact, the results from a pure SDI-sorting show that a higher SDI is associated with significantly lower returns during the crisis period. This finding is consistent with high-SDI funds taking on larger (idiosyncratic) risks that are likely to show in lower returns during the crisis period. In the second approach, we reestimate Table 4 and drop all observations in year 2008 to remove any potential effect of the crisis on our results. The results remain virtually unchanged as compared to Table 4 and therefore are not reported in a table. Third, we reestimate Table 4 for an augmented dataset including the TASS data from January 2009 to June 2009 to better account for the effect of the crisis on our results. Again we find the results to remain virtually unchanged and, to save space, do not report them in a table. ${ }^{28}$

\footnotetext{
${ }^{27}$ Unfortunately, we were unable to obtain CISDM data for the time period from January 2009 to June 2009.

${ }^{28}$ The results from the second and third approach are available from the authors upon request.
} 


\section{Conclusion}

This paper investigates the performance persistence of hedge funds over the time period from 1994 to 2008 based on a merged sample from the Lipper/TASS and the CISDM databases. We focus on long-term performance persistence and investigate time horizons of between 6 and 36 months because in light of notice and redemption periods the knowledge of shortterm performance persistence does not add a great deal of value for investors. We estimate alpha by benchmarking hedge fund returns against two alternative return-based factor models. Specifically, we establish a factor model in which we select the risk factors based on a stepwise regression approach, and compare the results to the widely used factor model proposed by Fung and Hsieh (2004). The dynamics in the factor exposures are accounted for by using a rolling-window regression approach.

We find alpha persistence of up to three years which is both economically and statistically highly significant. Persistence in raw returns is economically substantial for time horizons up to two years as well but statistically significant only over a six-month horizon. We then attempt to improve the performance persistence by identifying fund characteristics that are related to the probability of exhibiting performance persistence. We estimate panel probit regressions of an indicator variable for whether a fund exhibits performance persistence on a number of fund characteristics. The fund characteristics we include in this analysis are fund size, fund age, relative fund flows, a dummy variable whether the fund is closed to new investments, the length of the notice and the length of the redemption period, management and incentive fees, leverage, a dummy variable for whether the fund management is personally invested in the fund, and a 'Strategy Distinctiveness Index' (SDI) as originally suggested by Wang and Zheng (2008). This SDI attempts to measure manager skills and the uniqueness of the hedge funds' trading strategies. The results from the probit analysis show that all these fund characteristics are significantly related to the probability of observing performance persistence. However, by using two-way sorts and forming hedge fund portfolios not only based on the funds' historical alpha but also on one of these fund characteristics, we find only the SDI to have the ability to systematically improve performance persistence over 
time horizons up to two years. Our results are robust with respect to the factor model we use for measuring hedge fund alpha, the benchmark we use for calculating the SDI, the quantiles used to form portfolios (i.e., median, tercile, quartile, and quintile), and whether the analysis is based reported or desmoothed returns. Only during the credit crisis of 2008, the positive contribution of the SDI disappears indicating that high-SDI funds may take on larger idiosyncratic risks that show up in lower returns during crisis periods. 


\section{References}

Agarwal, V. and Naik, N. Y. (2000). Multi-period performance persistence analysis of hedge funds. Journal of Financial and Quantitative Analysis, 35(3):327-342.

Agarwal, V. and Naik, N. Y. (2004). Risk and portfolio decisions involving hedge funds. The Review of Financial Studies, 17(1):63-98.

Aggarwal, R. and Jorion, P. (2010). The performance of emerging hedge funds and managers. Journal of Financial Economics, 96(2):238-256.

Ammann, M., Huber, O., and Schmid, M. (2010). Has hedge fund alpha disappeared? Journal of Investment Management, forthcoming.

Ammann, M. and Moerth, P. (2008). Impact of fund size and fund flows on hedge fund performance. The Journal of Alternative Investments, 11(1):78-96.

Aragon, G. O. (2007). Share restrictions and asset pricing: Evidence from the hedge fund industry. Journal of Financial Economics, 83(1):33-58.

Bares, P.-A., Gibson, R., and Gyger, S. (2003). Performance in the hedge fund industry: An analysis of short and long-term persistence. Journal of Alternative Investments, 6(3):25-41.

Boyson, N. M. (2008). Do hedge funds exhibit performance persistence? A new approach. Financial Analysts Journal, 64(6):27-44.

Boyson, N. M. (2010). Implicit incentives and reputational herding by hedge fund managers. Journal of Empirical Finance, 17(3):283-299.

Capocci, D. (2007). The sustainability of hedge fund performance: New insights. Journal of Financial Management, 1(2):59-86.

Capocci, D. and Huebner, G. (2004). Analysis of hedge fund performance. Journal of Empirical Finance, 11(1):55-89.

Carhart, M. (1997). On persistence in mutual fund performance. Journal of Finance, $52(1): 57-82$.

Edwards, F. and Caglayan, M. (2001). Hedge fund performance and manager skill. Journal of Futures Markets, 21(11):1003-1028.

Eling, M. (2009). Does hedge fund performance persist? overview and new empirical evidence. European Financial Management, 15(2):362-401.

Ennis, R. and Sebastian, M. (2003). A critical look at the case for hedge funds: Lessons from the bubble. Journal of Portfolio Management, 10(2):103-112. 
Fama, E. and French, F. (1993). Common risk factors in the returns on stocks and bonds. Journal of Financial Economics, 33(1):3-56.

Fama, E. and MacBeth, J. (1973). Risk, return and equilibrium: Empirical tests. Journal of Political Economy, 81(3):607-636.

Fung, W. and Hsieh, D. A. (2000). Performance characteristics of hedge funds and commodity funds: Natural vs. spurious biases. Journal of Financial and Quantitative Analysis, 35(3):291-307.

Fung, W. and Hsieh, D. A. (2001). The risk in hedge fund strategies: Theory and evidence from trend followers. The Review of Financial Studies, 14(2):313-341.

Fung, W. and Hsieh, D. A. (2004). Hedge fund benchmarks: A risk based approach. Financial Analysts Journal, 60(5):65-80.

Fung, W., Hsieh, D. A., Naik, N. Y., and Ramadorai, T. (2008). Hedge funds: Performance, risk, and capital formation. Journal of Finance, 63(4):1777-1803.

Getmansky, M., Lo, A. W., and Makarov, I. (2004a). An econometric model of serial correlation and illiquidity in hedge fund returns. Journal of Financial Economics, 74(3):529-609.

Getmansky, M., Lo, A. W., and Mei, S. (2004b). Sifting through the wreckage: Lessons from recent hedge-fund liquidations. Journal of Investment Management, 2(4):6-38.

Harri, A. and Brorsen, B. (2004). Performance persistence and the source of returns for hedge funds. Applied Financial Economics, 14(2):131-141.

Hendricks, D., Patel, P., and Zeckhauser, R. (1993). Hot hands in mutual funds: Short-run persitence of relative performance, 1974-1988. Journal of Finance, 48(1):93-130.

Hodder, J., Jackwerth, J. C., and Kolokolova, O. (2009). Recovering delisting returns of hedge funds. Working Paper. University of Konstanz.

Jagannathan, R., Malakhov, A., and Novikov, D. (2010). Do hot hands exist among hedge fund managers? An empirical evaluation. Journal of Finance, 65(1):217-255.

Kosowski, R., Naik, N. Y., and Teo, M. (2007). Do hedge funds deliver alpha? A bayesian and bootstrap analysis. Journal of Financial Economics, 84(1):229-264.

Kosowski, R., Timmermann, A., Wermers, R., and White, H. (2006). Can mutual fund "stars" really pick stocks? New evidence from a bootstrap analysis. Journal of Finance, 61(6):2551-2595.

Kumar, P. (2008). Hedge fund characteristics and performance persistence. Working Paper, MIT. 
Malkiel, B. G. and Atanu, S. (2005). Hedge funds: risk and return. Financial Analysts Journal, 47(6):80-88.

Manser, S. and Schmid, M. (2009). The performance persistence of equity long/short hedge funds. Journal of Derivatives and Hedge Funds, 15(1):51-69.

Naik, N. Y., Ramadorai, T., and Stromqvist, M. (2007). Capacity constraints and hedge fund strategy returns. European Financial Management, 13(2):239-256.

Sun, Z., Wang, A., and Zheng, L. (2009). The road less traveled: Strategy distinctiveness and hedge fund performance. Working Paper. University of California Irvine.

Teo, M. (2009). The geography of hedge funds. The Review of Financial Studies, 22(9):35213561.

Titman, S. and Tiu, C. (2008). Do the best hedge funds hedge? Working Paper. University of Texas at Austin.

Wang, A. and Zheng, L. (2008). Strategy distinctiveness and hedge fund performance. Working Paper. University of California, Irvine. 
Table 1: Factor selection for each hedge fund strategy

The table reports the factors selected from a forward stepwise regression approach applied to equallyweighted strategy indices comprising our sample funds within each strategy. These risk factors are selected from 23 potential risk factors. The full choice of factors is provided in Appendix A. We require significance at the $5 \%$ level for factors be included (and 10\% to remain) in the regression models.

\begin{tabular}{lll}
\hline Convertible Arbitrage & Dedicated Short Bias & Emerging Markets \\
\hline CS High Yield Index II & SPX ATM Call & MOM* \\
ML Convertible Bond Index (IG) & Russel 3000 & MSCI EM \\
Russel 3000 & HML* & Dollar Index spot \\
MSCI EM & SMB* & \\
& MOM* &
\end{tabular}

\begin{tabular}{lll}
\hline Equity Market Neutral & Event Driven & Fixed Income Arbitrage \\
\hline MOM* $^{*}$ SPX Put 92.5\% & SPX Put 92.5\% & CS High Yield Index II \\
SPX Call 107.5\% & CS High Yield Index II & Delta Baa Spread* \\
CS High Yield Index II & SMB* & \\
PTFSSTK** & SPX ATM Call & \\
& MSCI EM & \\
& HML* & \\
\hline & PTFSSTK** & \\
Global Macro & & \\
\hline Delta 3M TED Spread* & Long/Short Equity & Managed Futures \\
Citi World Govt Bond Index & SMSsel 3000 & PTFSFX** \\
MSCI EM & MSCI EM & Citi World Govt Bond Index \\
PTFSFX** & MOM* & PTFSBD** \\
MOM* & PTFSSTK** & S\&P GS Commodity Index \\
& MSCI World Ex US & MOM* \\
& S\&P/Citi World REIT & \\
\hline
\end{tabular}

\section{Multi-Strategy}

\begin{tabular}{l}
\hline MSCI EM \\
S\&P/Citi World REIT \\
PTFSSTK** \\
VIX \\
SMB* \\
${ }^{*}$ All indices are excess returns over the $1 m$ T-Bill except those indicated with an asterisk $\left(^{*}\right)$ \\
${ }^{* *}$ Primitive Trend Following Strategies on: BD: Bonds, STK: Stocks, FX: Currencies, COM: Commodities \\
\hline
\end{tabular}




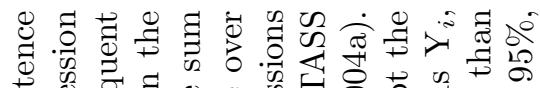

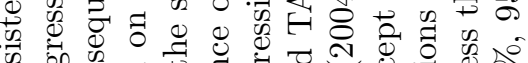

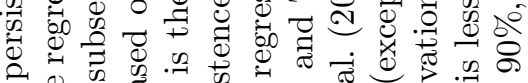

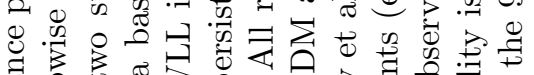

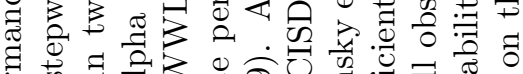

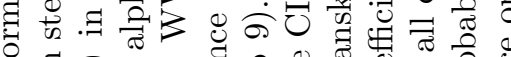

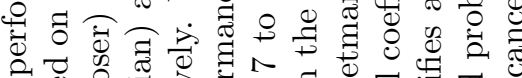

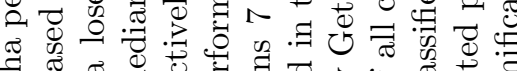
을

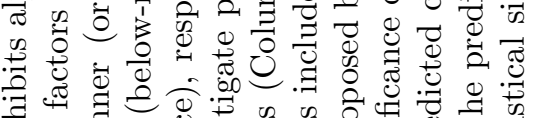

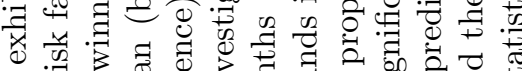

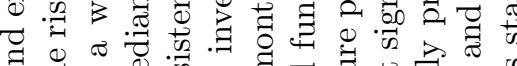

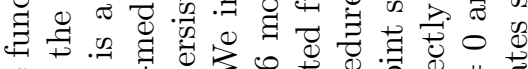

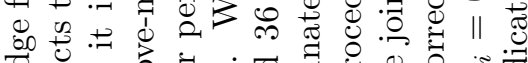

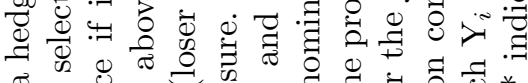

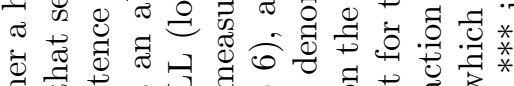

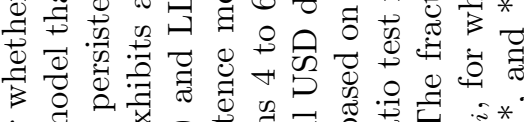

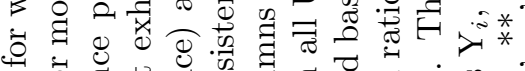

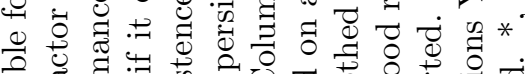

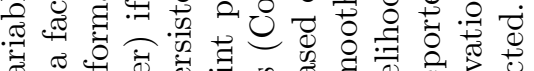

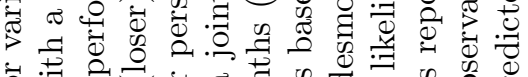
to

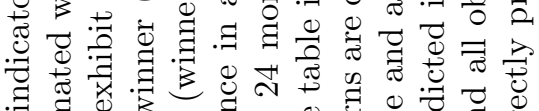

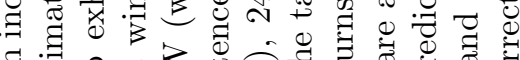

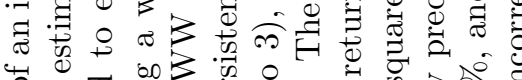

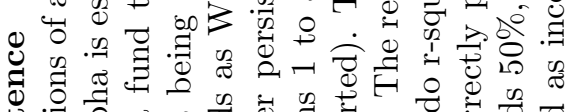

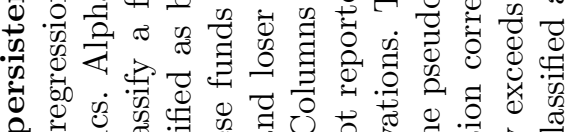

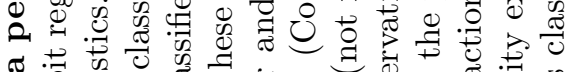

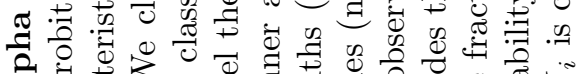

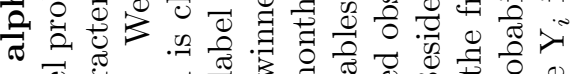

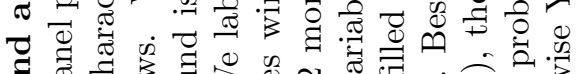

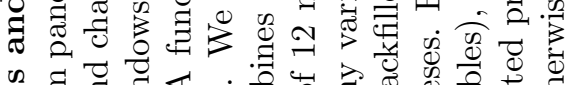

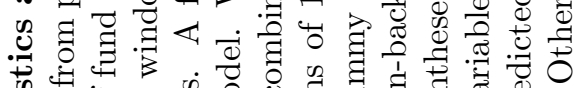

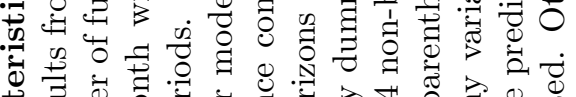

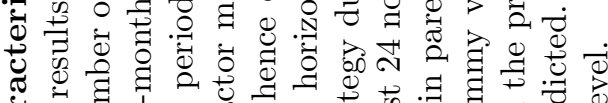

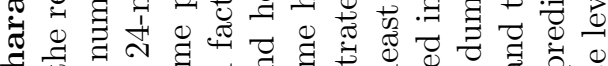
on

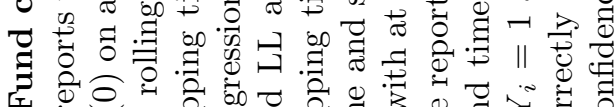

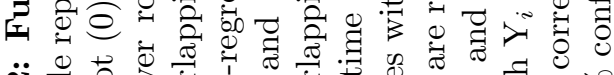

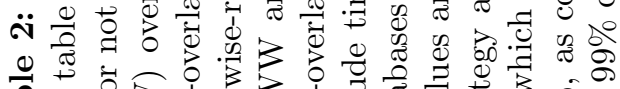

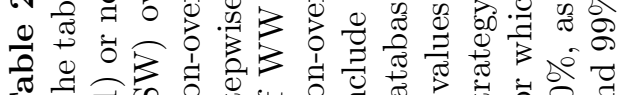

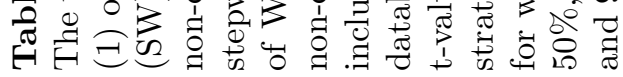

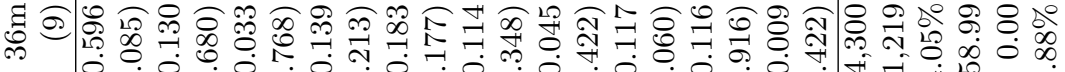

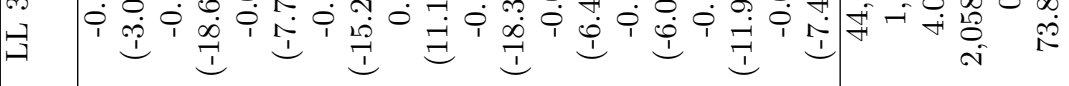

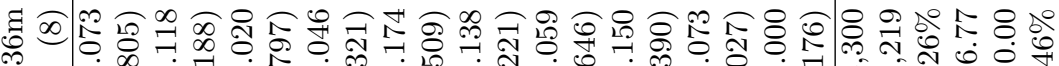

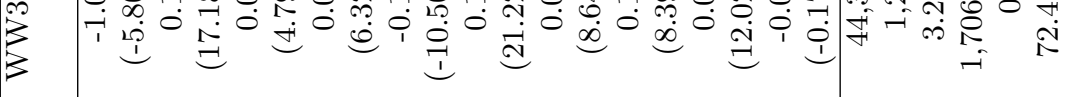

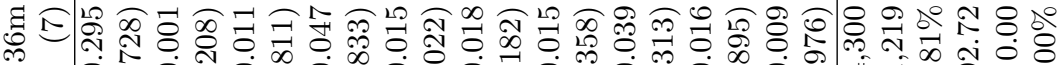
当 3

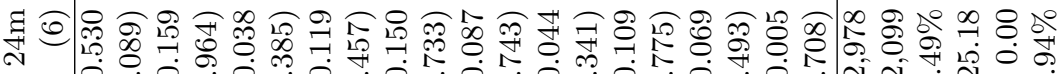

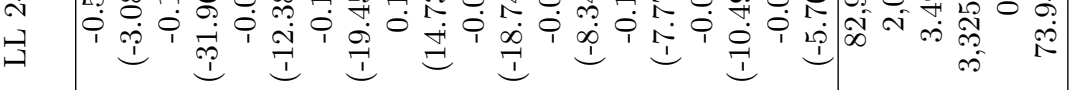

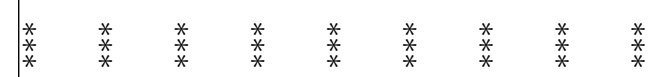

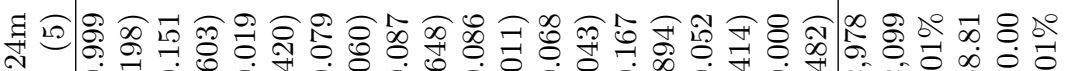

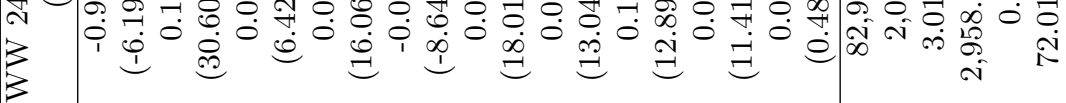

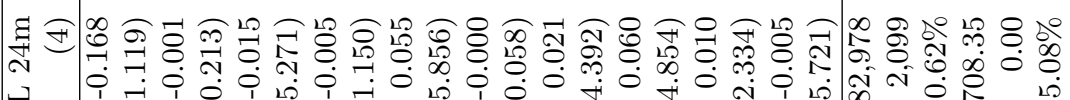

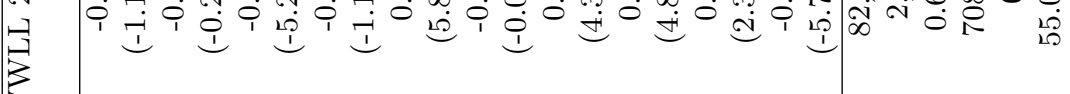
3

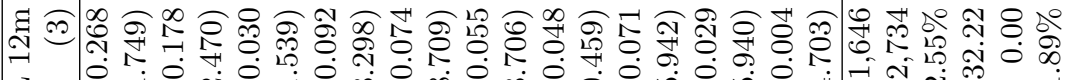

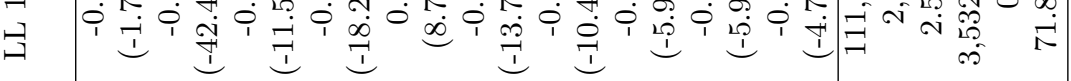

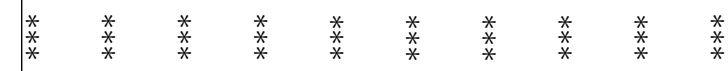

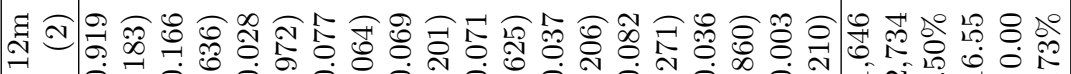

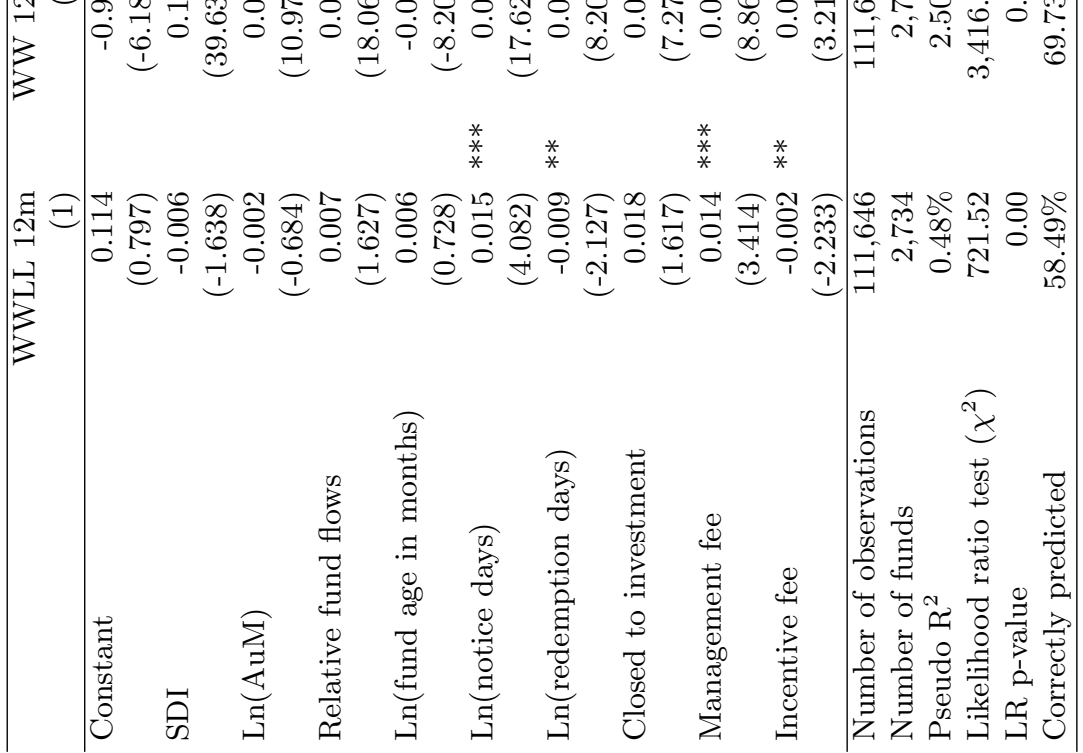




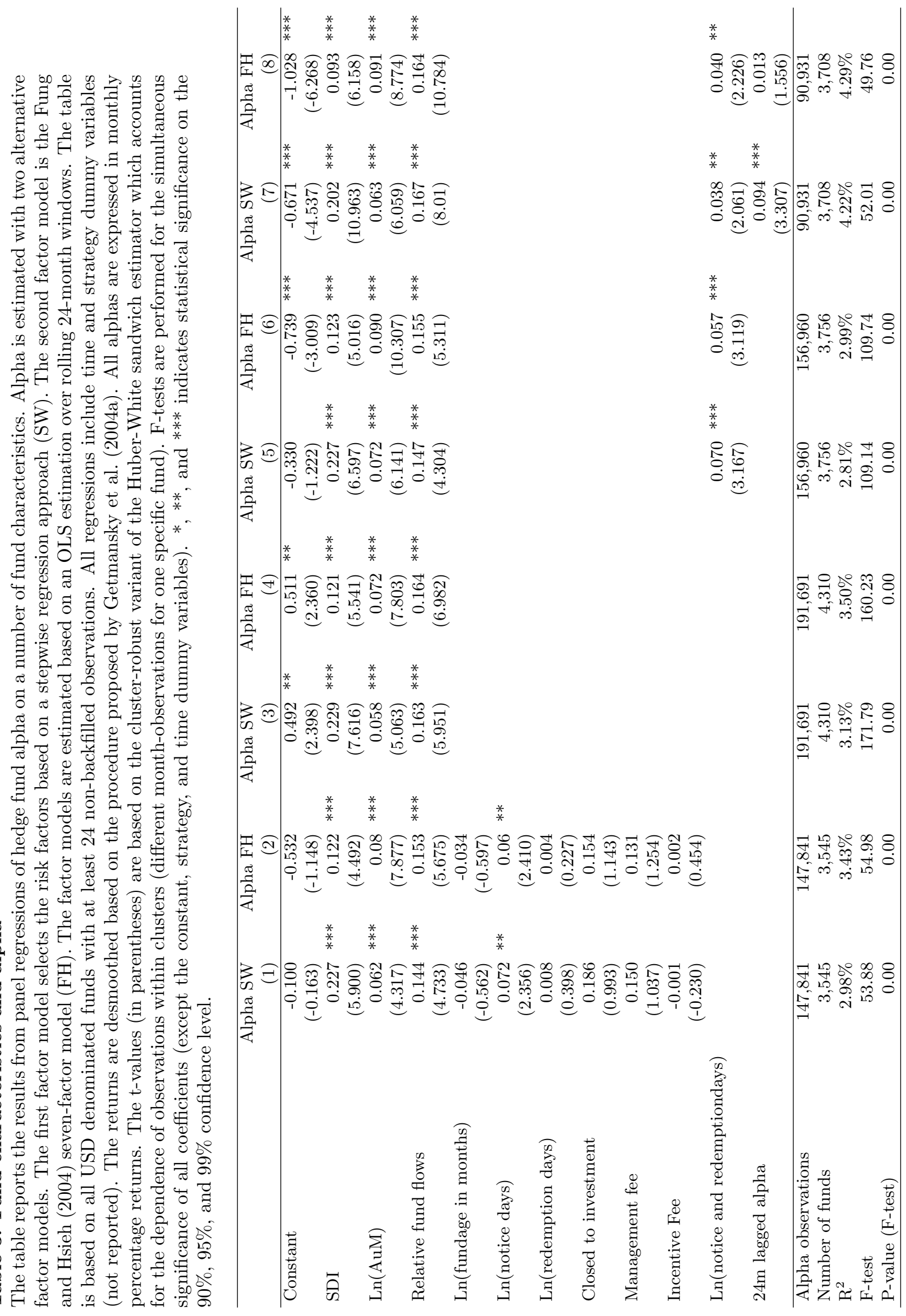




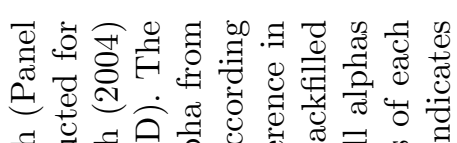

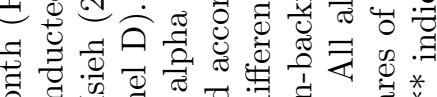

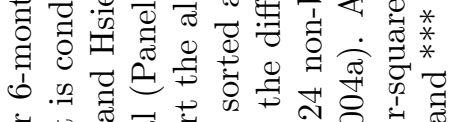

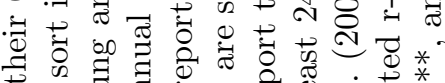

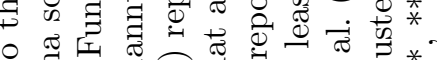

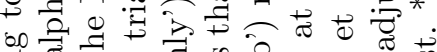

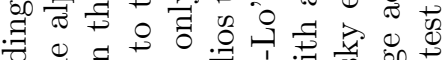

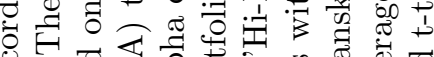

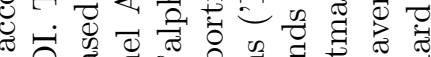

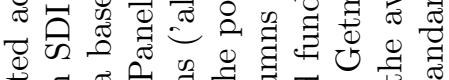

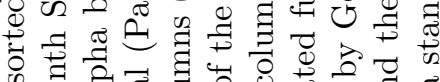

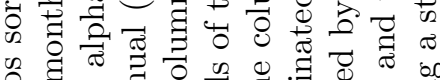

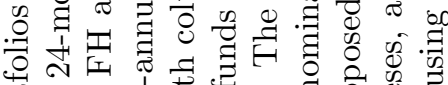

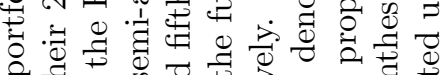

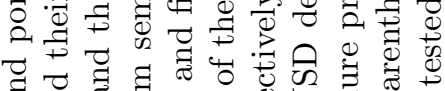

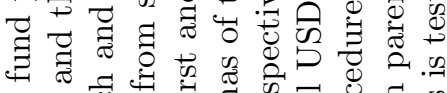

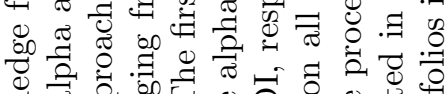

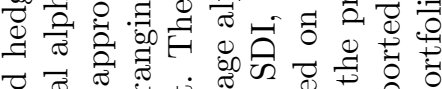

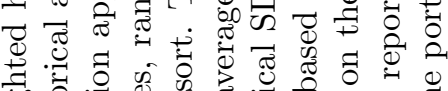

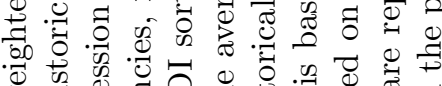

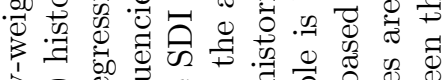

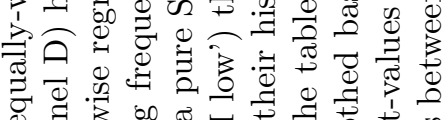

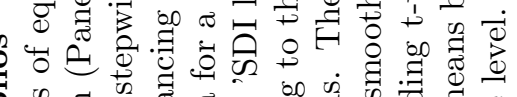

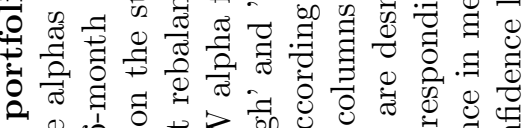

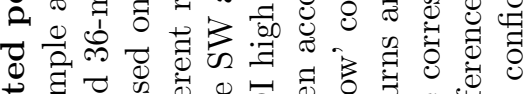

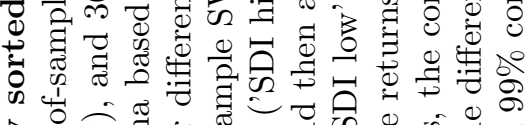

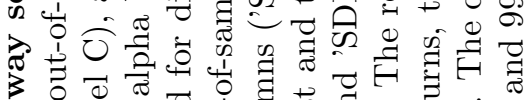

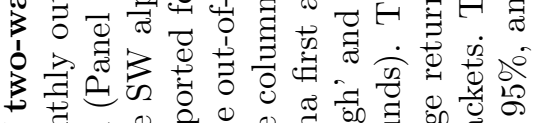
等 等

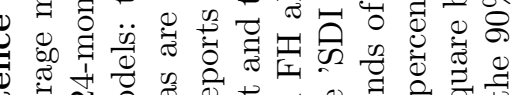

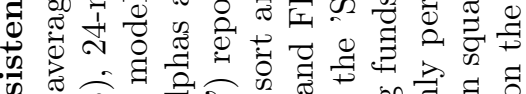

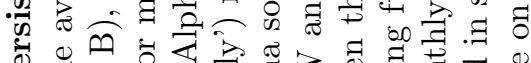

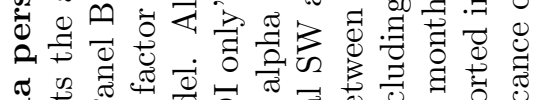

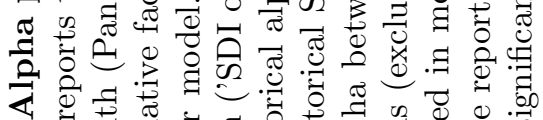

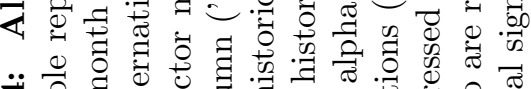

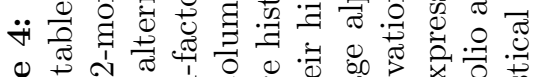

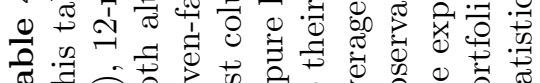

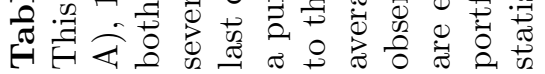

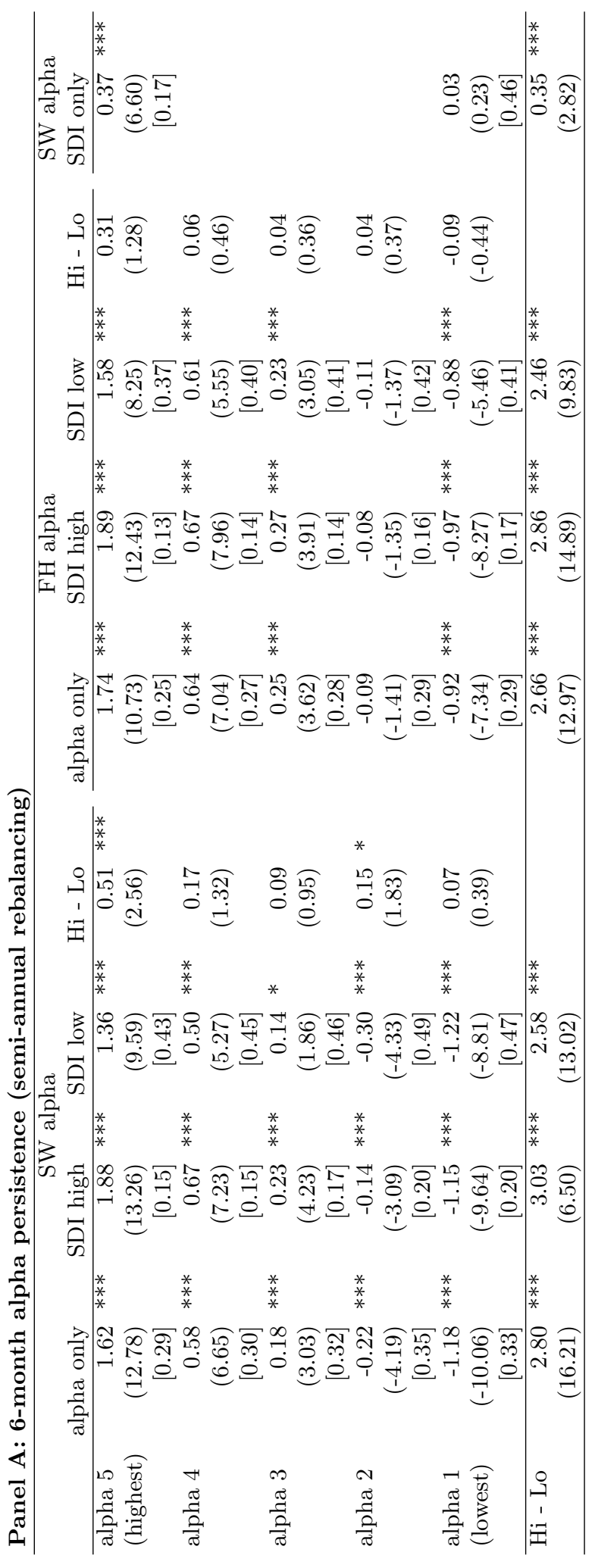




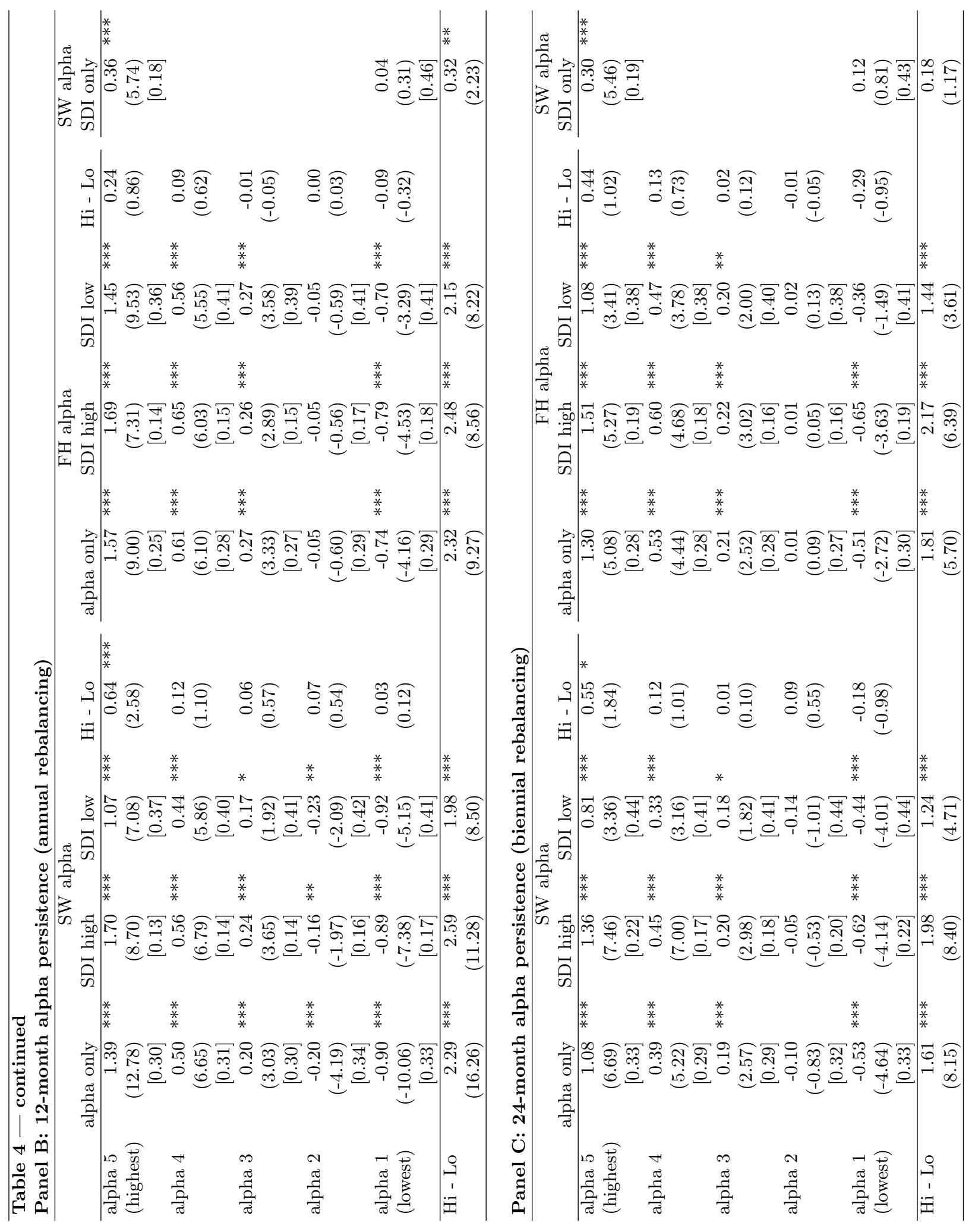




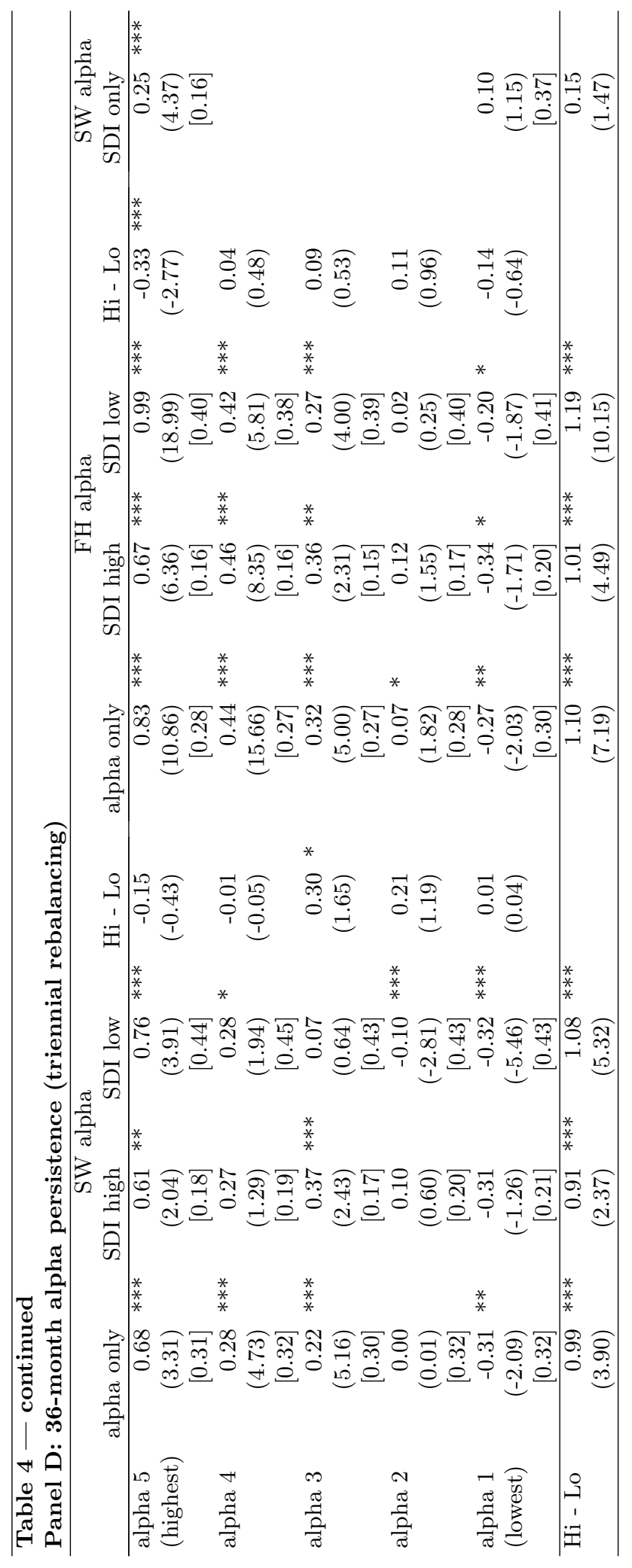




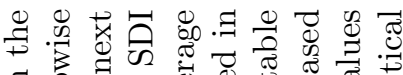

:

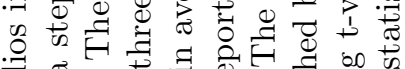

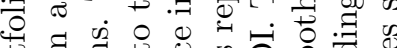

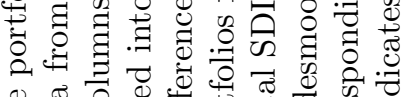

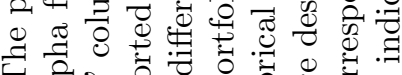

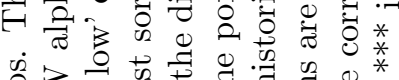

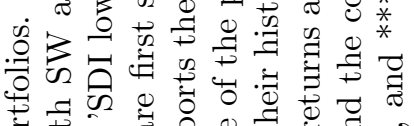

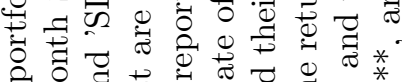

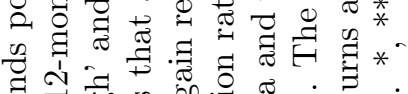

声 空

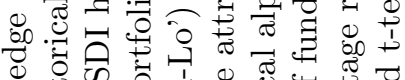

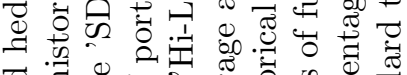

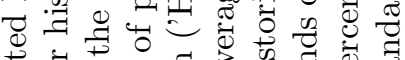

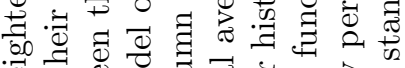

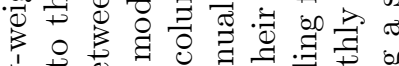

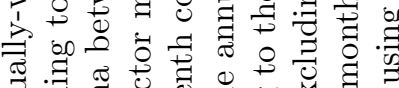
Ð

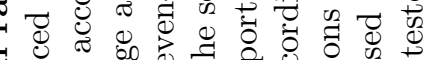
₹ 0

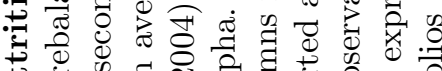

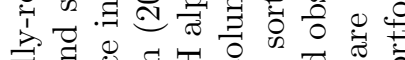

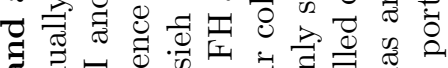
สี 㐘

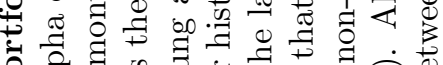

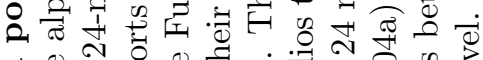

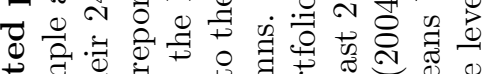

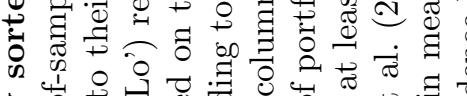

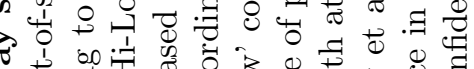

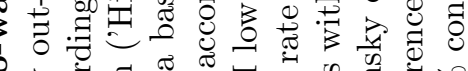

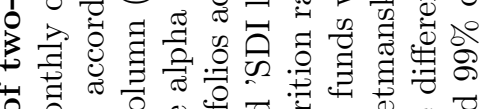

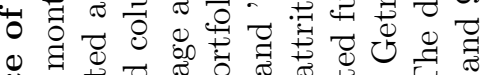

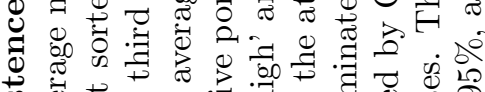

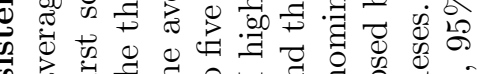

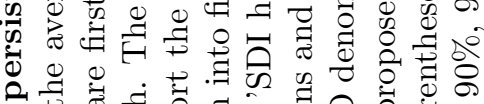
ڤ.

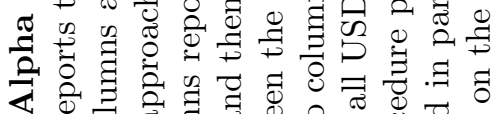

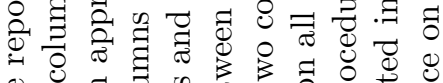

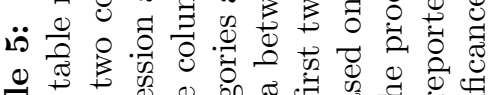

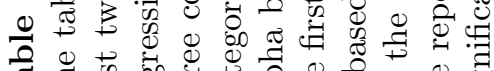

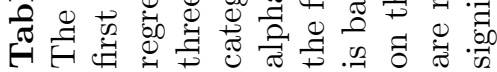

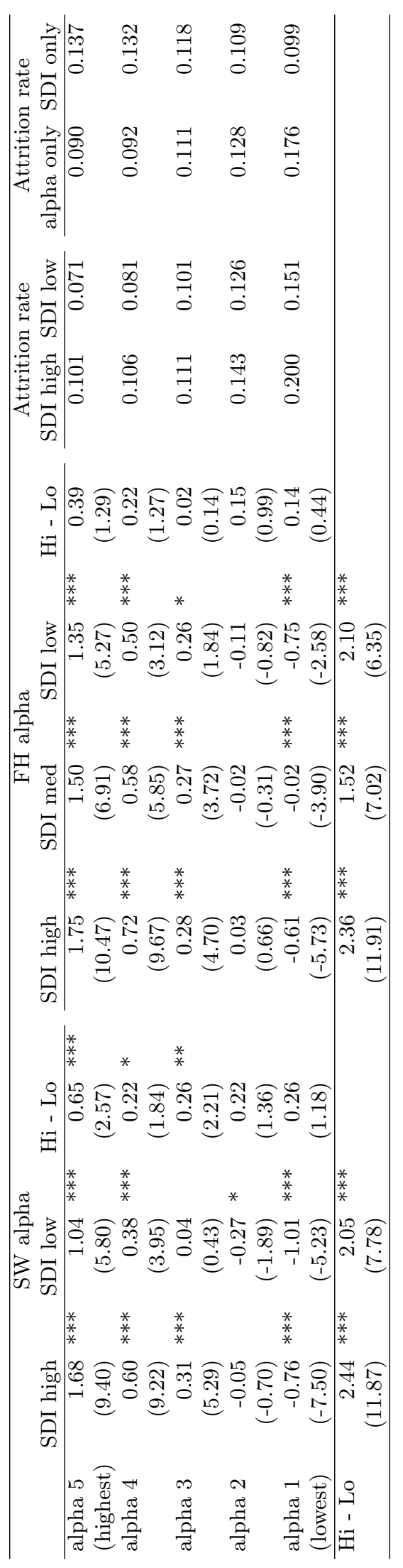




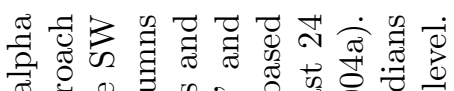

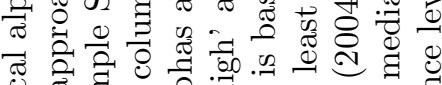

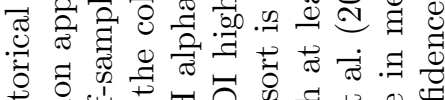

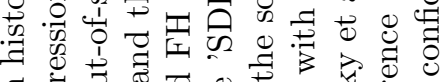

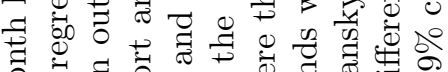

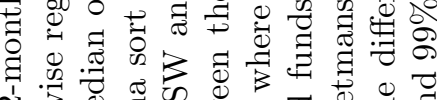

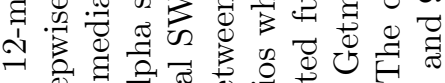

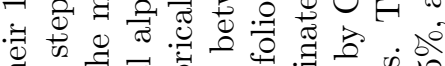

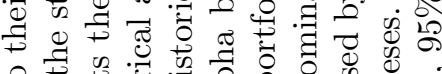

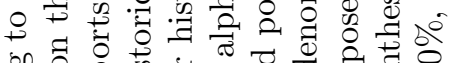

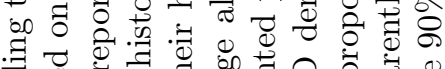

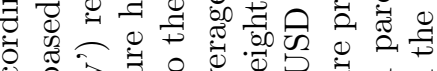

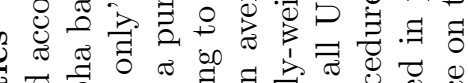

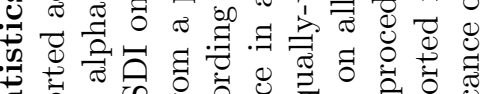

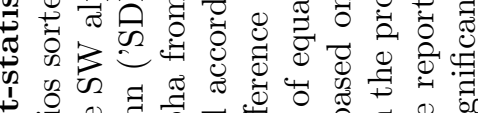

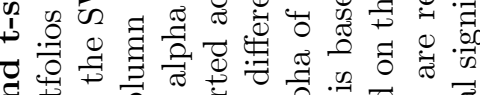

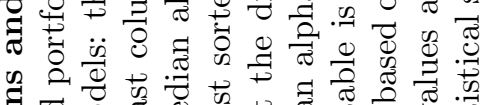

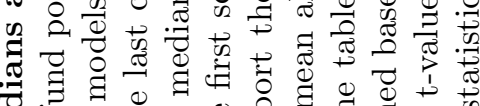

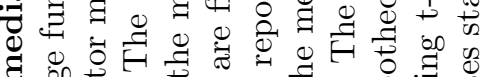
然

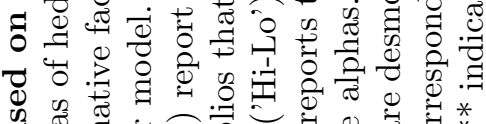

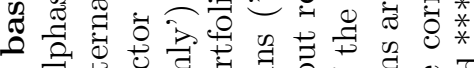

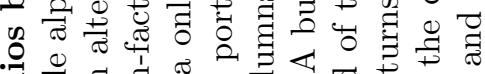

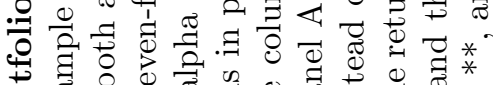

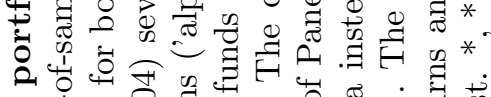

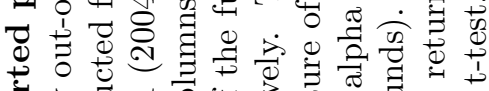

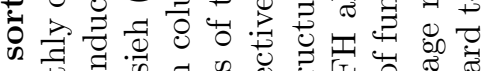

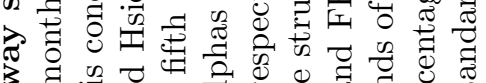

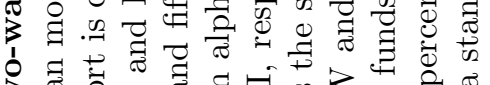

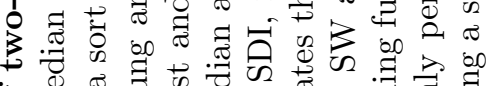

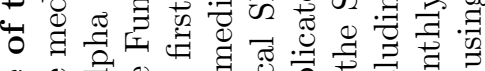

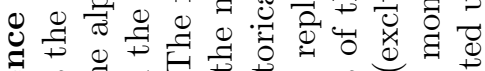

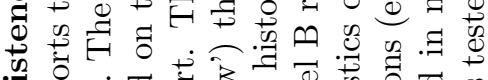

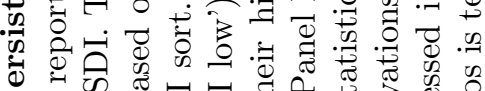
응

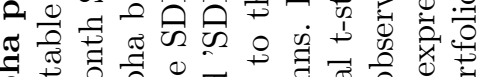

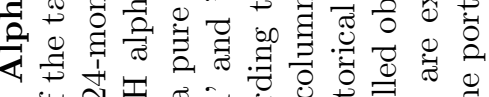

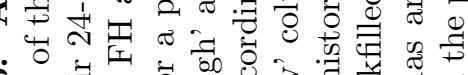

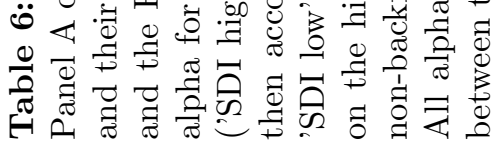

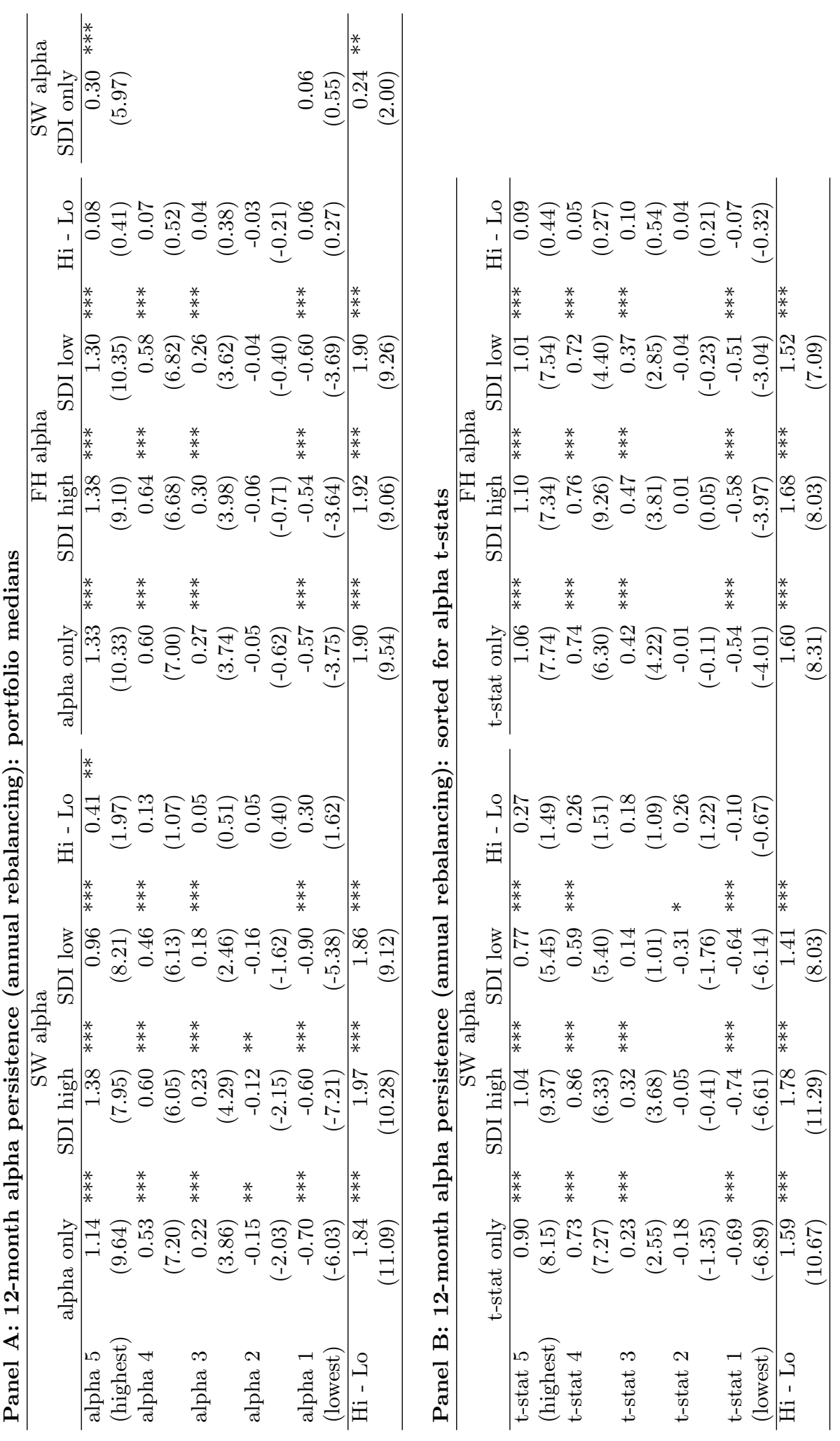




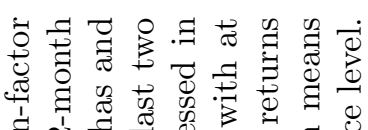
근

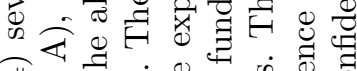

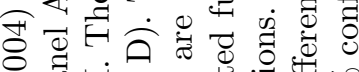

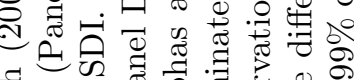
월 चี สี 60.4 긍

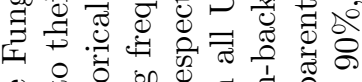

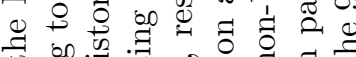

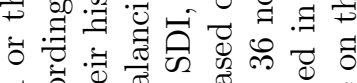
旸 政 究 ๙

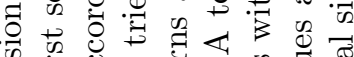
की

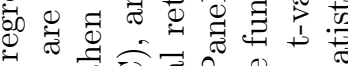
प क

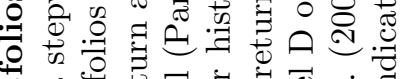

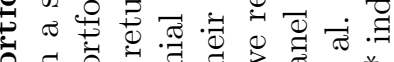

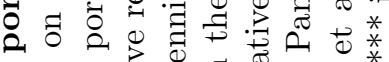

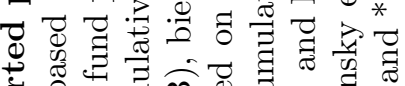

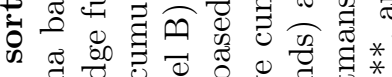

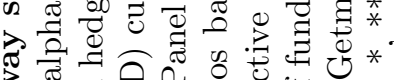

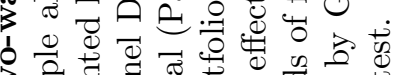

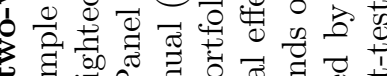

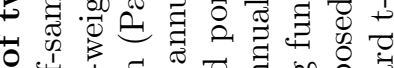

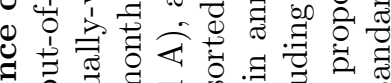

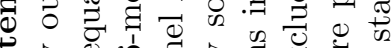

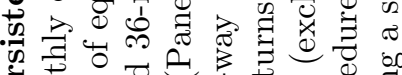

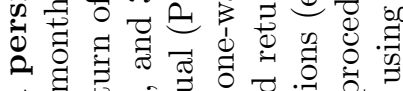

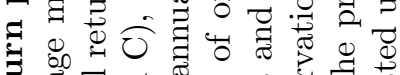

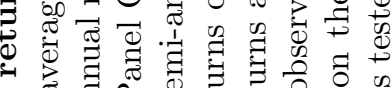

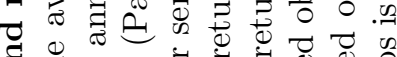

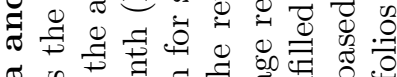

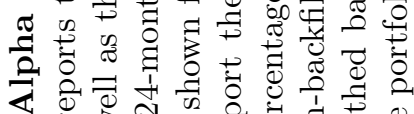

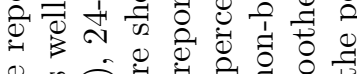

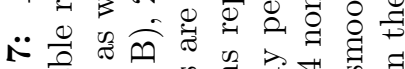
음

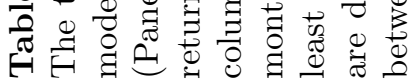

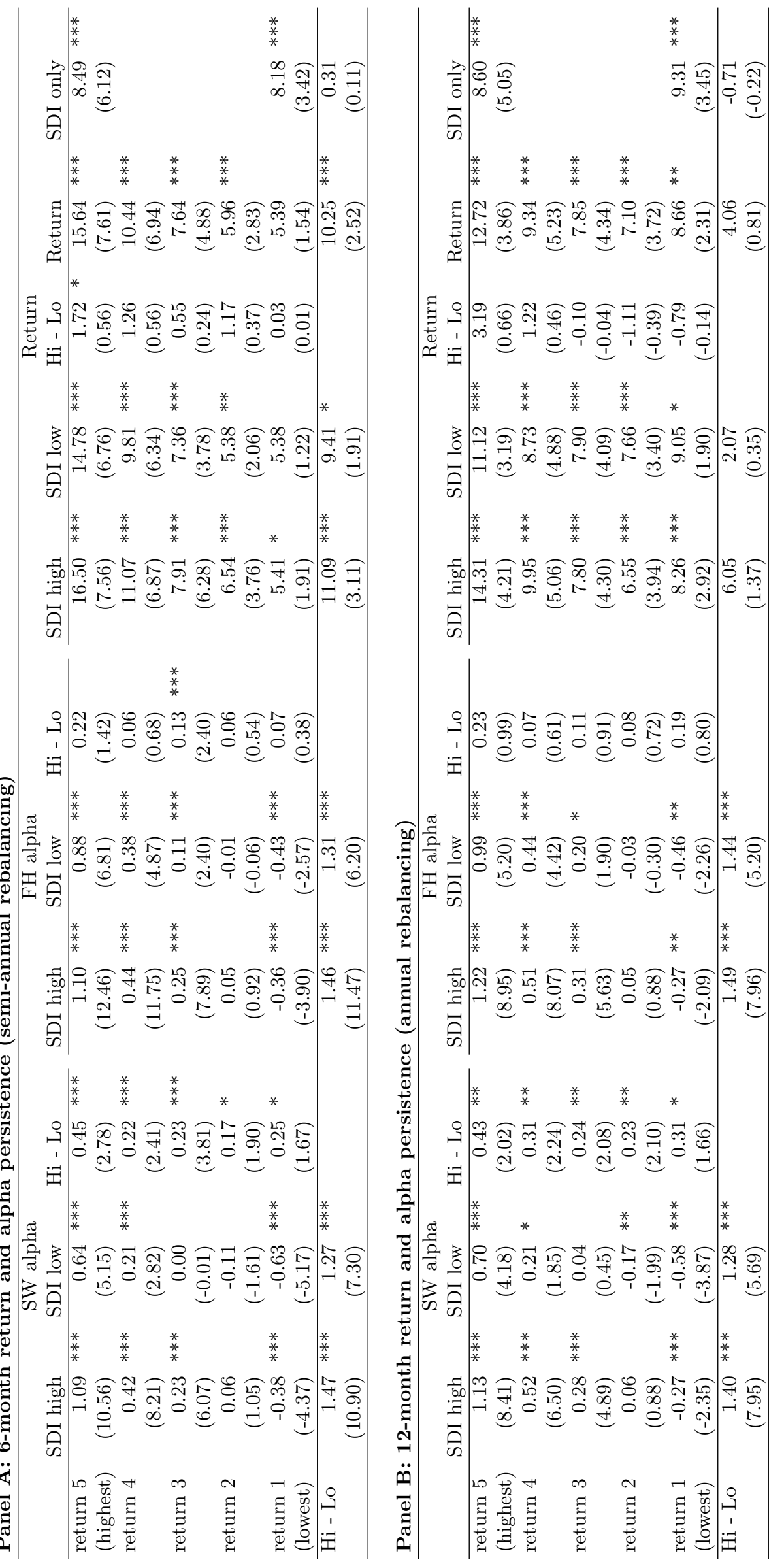




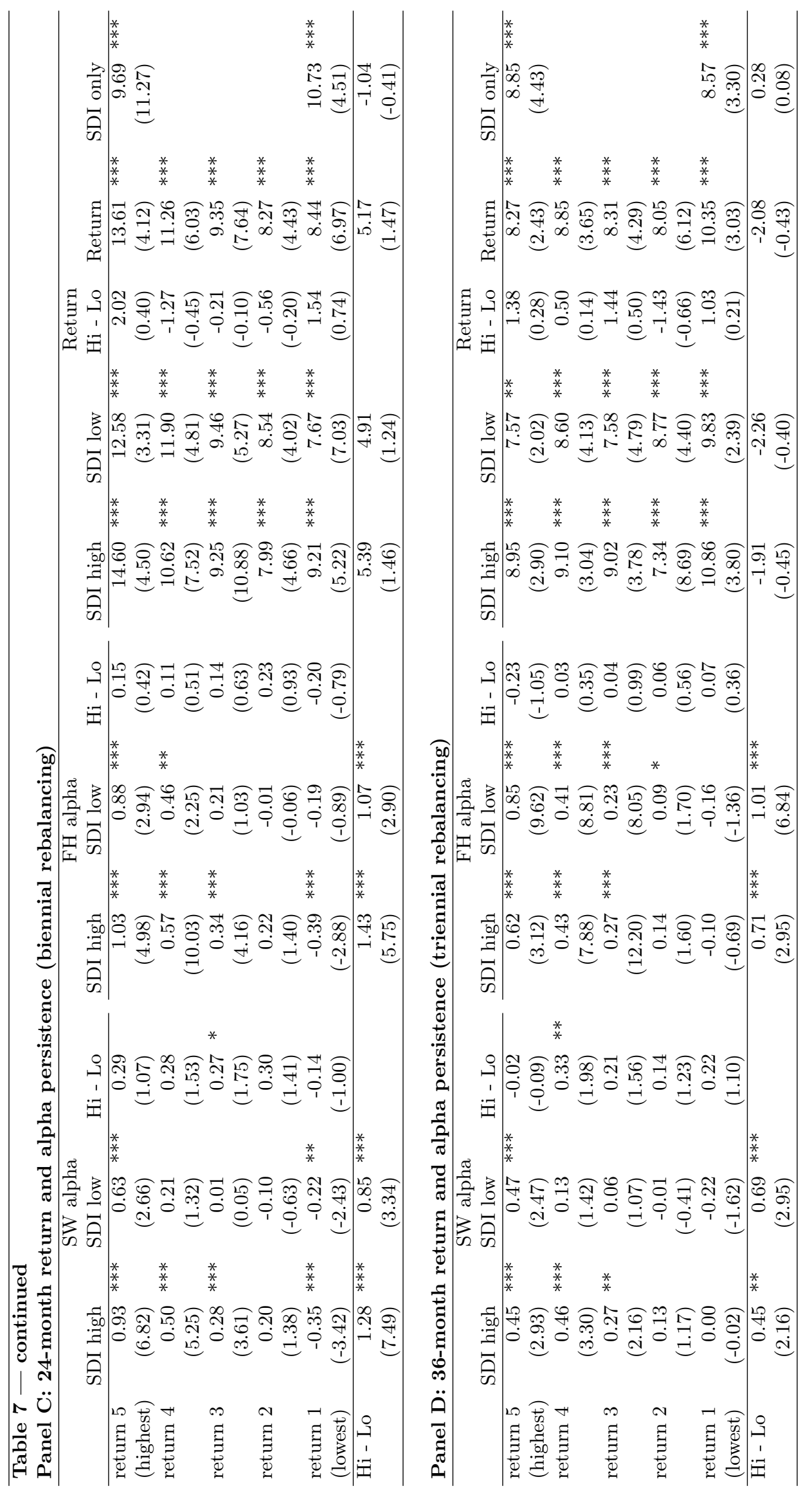




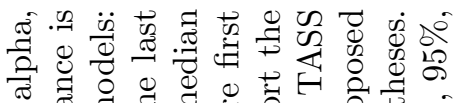

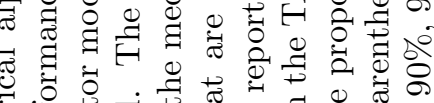

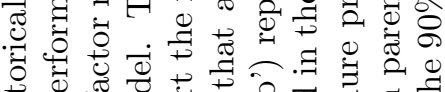

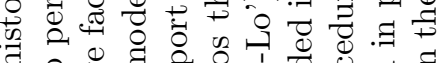

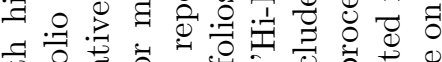

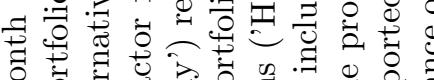

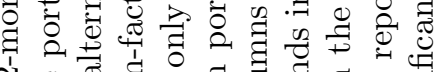

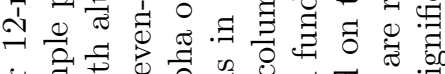

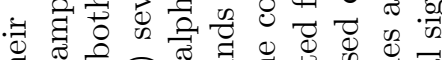

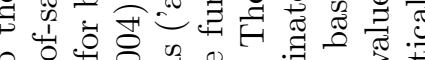

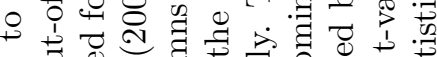

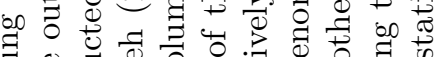

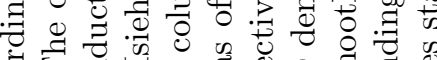

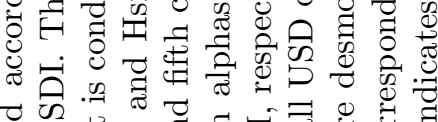

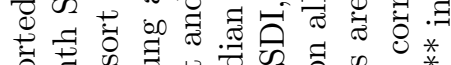

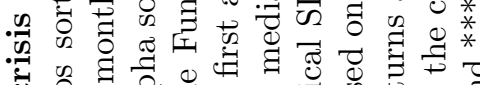

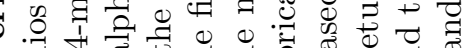
o

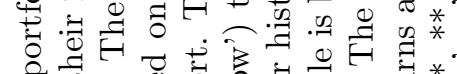

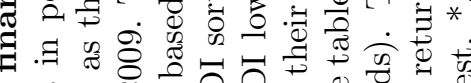
乎

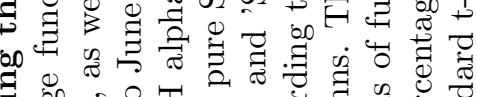

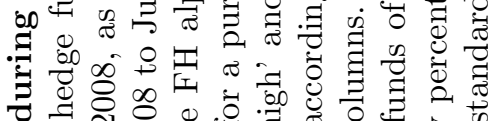
讨

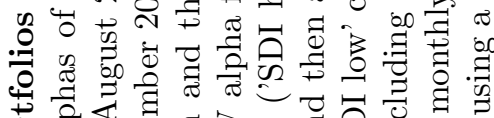

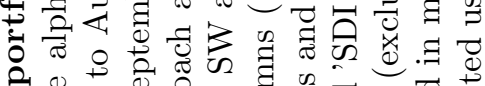

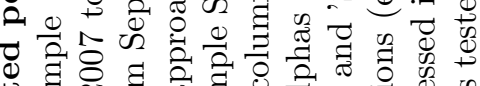

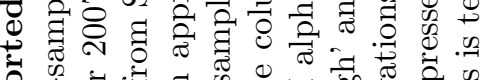

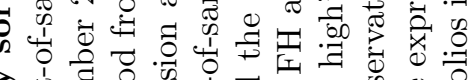

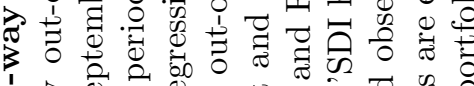

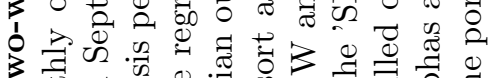

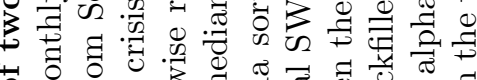

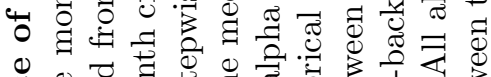

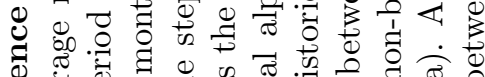

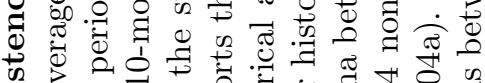

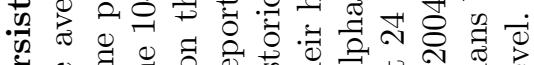

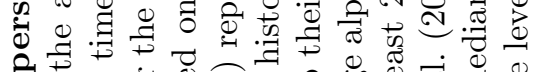

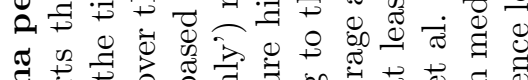

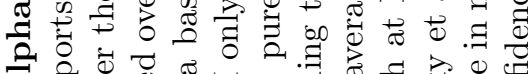

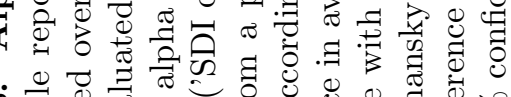

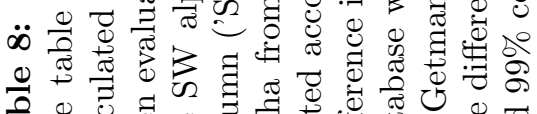

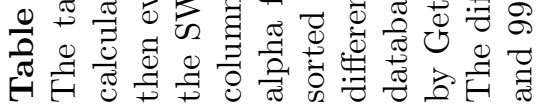

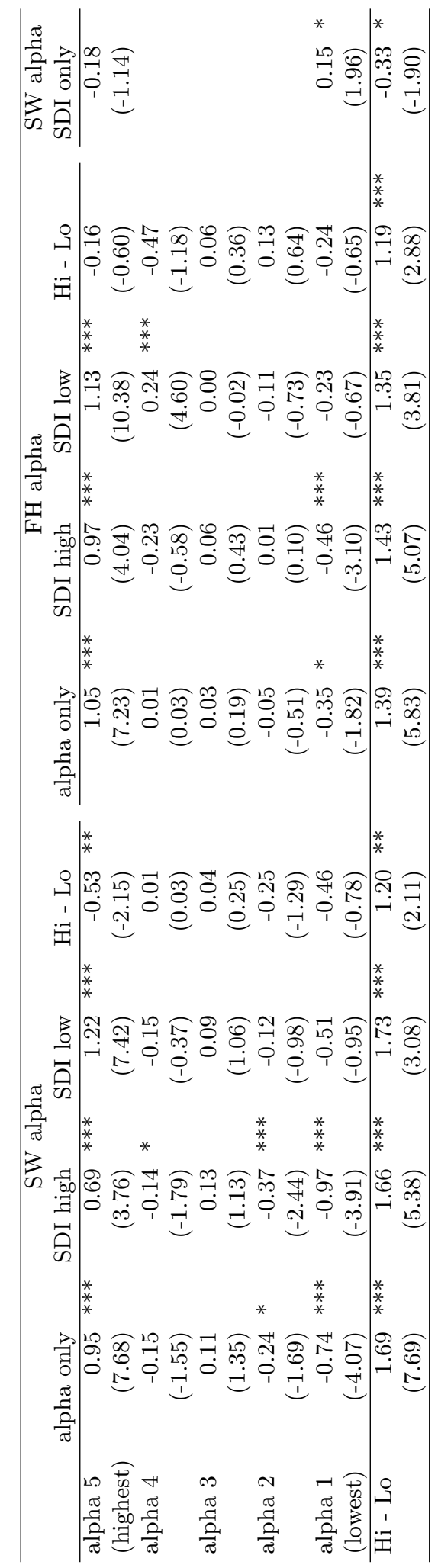




\section{Appendix A: Factors considered for the factor model}

- Equity indices: excess returns of the following indices: MSCI World EX USA TR USD, MSCI Emerging Markets TR (USD), MSCI Emerging Markets Latam TR (USD), MSCI Emerging Markets ASIA TR (USD), Russel 3000 TR Index

- Bond indices / credit risk / interest rates: excess returns, yields, and first differences of the following indices: Citi World Government Bond Index excess return, CS High Yield Index II excess return, monthly first difference of the Moody's Baa Corporate Bond Index 30yr 100m minus the 30yr generic US government bond yield, $3 \mathrm{~m}$ Treasury-Eurodollar spread (TED spread)

- Currency index: excess return of the US Dollar Index return

- Options/ volatility/ dynamic trading strategies: excess returns of the following indices/portfolios: S\&P 500 Volatility Index, SMB (Fama and French, 1993), HML (Fama and French, 1993), MOM (Carhart, 1997) ${ }^{29}$, Black Scholes S\&P 500 ATM/OTM call and put options based on historical implied volatilities and historical realized dividend yields and interest rates of the following moneyness: ATM call, 107.5\% call, $92.5 \%$ put, ATM put, lookback straddles on equities, commodities, currencies, and bonds ${ }^{30}$

- Commodities: excess returns of the S\&P Goldman Sachs Commodity Index (SP GCSI) total return

- Real estate: excess returns of the S\&P/Citigroup World REIT Index TR

- Convertible bonds: excess returns for the Merrill Lynch Convertible Bond Index (investment grade)

\footnotetext{
${ }^{29}$ For the US market, these factors are available from the homepage of Kenneth French.

${ }^{30}$ The returns of these primitive trend following strategies (PTFSBD: Return of PTFS Bond lookback straddle, PTFSFX: Return of PTFS Currency Lookback Straddle, PTFSCOM: Return of PTFS Commodity Lookback Straddle, PTFSIR: Return of PTFS Short Term Interest Rate Lookback Straddle, PTFSSTK: Return of PTFS Stock Index Lookback Straddle) can be downloaded from the homepage of David Hsieh at: http://faculty.fuqua.duke.edu/ dah7/DataLibrary/TF-Fac.xls.
} 